\title{
Omentum and bone marrow: how adipocyte-rich organs create tumor microenvironments conducive for metastatic progression
}

Halina Chkourko Gusky ${ }^{1}$, Jonathan Diedrich ${ }^{1,2}$, Ormond A. MacDougald ${ }^{3,4}$, and Izabela Podgorski ${ }^{1,2}$

${ }^{1}$ Department of Pharmacology, ${ }^{2}$ Karmanos Cancer Institute, Wayne State University School of Medicine, Detroit, MI 48201; ${ }^{3}$ Department of Molecular \& Integrative Physiology, University of Michigan, Ann Arbor, Michigan, USA; ${ }^{4}$ Department of Internal Medicine, University of Michigan, Ann Arbor, Michigan, USA.

Corresponding Author:

Izabela Podgorski

Wayne State University School of Medicine

Department of Pharmacology

540 E. Canfield, Rm 6304

Detroit, MI 48201

Tel: (313) 577-0514

Fax:(313) 577-6739

E-mail: ipodgors@med.wayne.edu

RUNNING TITLE: Omentum and Bone Marrow in Tumor Metastasis

The authors disclose no potential conflicts of interest

Keywords: adipose tissue, WAT, MAT, omental metastasis, bone metastasis

Number of text pages: 20

Number of figures: 1

Number of tables: 4

This is the author manuscript accepted for publication and has undergone full peer review but has not been through the copyediting, typesetting, pagination and proofreading process, which may lead to differences between this version and the Version of Record. Please cite this article as doi: $10.1111 /$ obr.12450

This article is protected by copyright. All rights reserved. 


\section{Grant support:}

IP is supported NIH/NCI 1 R01 CA181189-01

OAM is supported by RO1 DK095705, RO1 DK62876, R24 DK092759

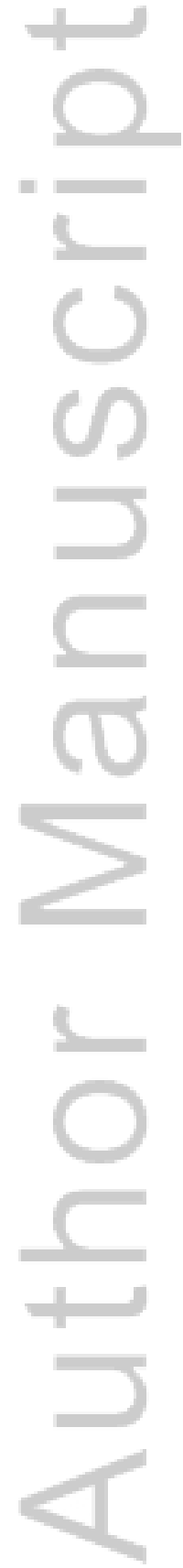

This article is protected by copyright. All rights reserved. 


\begin{abstract}
A number of clinical studies have linked adiposity with increased cancer incidence, progression and metastasis and adipose tissue is now being credited with both systemic and local effects on tumor development and survival. Adipocytes, a major component of benign adipose tissue, represent a significant source of lipids, cytokines and adipokines and their presence in the tumor microenvironment substantially affects cellular trafficking, signaling and metabolism. Cancers that have a high predisposition to metastasize to the adipocyterich host organs are likely to be particularly affected by the presence of adipocytes. Although our understanding of how adipocytes influence tumor progression has grown significantly over the last several years, the mechanisms by which adipocytes regulate the metastatic niche are not well-understood. In this review, we focus on the omentum, a visceral white adipose tissue (WAT) depot, and the bone, a depot for marrow adipose tissue (MAT), as two distinct adipocyte-rich organs that share common characteristic: they are both sites of significant metastatic growth. We highlight major differences in origin and function of each of these adipose depots and reveal potential common characteristics that make them environments that are attractive and conducive to secondary tumor growth. Special attention is given to how omental and marrow adipocytes modulate the tumor microenvironment by promoting angiogenesis, affecting immune cells and altering metabolism to support growth and survival of metastatic cancer cells.
\end{abstract}

This article is protected by copyright. All rights reserved. 
With many epidemiological studies raising awareness and correlating Western diet and metabolic disturbances with cancer progression and metastatic development, it is imperative to understand the molecular basis for adiposity-driven tumorigenesis. Overeating and sedentary lifestyles are clearly predominant reasons for elevated fat depots, but other physiological factors and medical conditions such as age and hormonal status are associated with adipocyte hypertrophy, adipogenesis and increased body mass index (BMI) [1, 2]. General involvement of adipocytes in lipid storage and secretion of endocrine factors underscores the importance of adipose tissue in metabolism and inflammation [3-8]. Our current body of knowledge indicates that various adipose depots exhibit important differences in adipogenic progenitors, metabolism and effects they exert on system organs. Herein we will review how omentum, an organ that is naturally rich in adipocytes, and bone marrow, which becomes fatty in response to physiological and pathological factors, contribute to creating a niche that attracts and supports secondary metastatic tumor growth.

\section{Metastatic Microenvironment Generated by White Adipose Tissue (WAT).}

According to National Cancer Institute, peritoneal metastases are the most common occurrences in the spread of ovarian, colorectal, gastric, pancreatic and uterine cancers [9], with the omentum often being the predominant metastatic site within the peritoneum $[10,11]$. Direct intraperitoneal seeding is the most common route of dissemination of cancer cells to omentum because of the proximity of the primary abdominal tumors [10]. Cancer cells that are shed from the primary tumor are initially spread via peritoneal fluid and eventually by the ascites accumulating in the abdominal cavity due to disruption of lymphatic system [12, 13]. Dissemination of ovarian tumors through the vasculature as a primary mode of metastasis is very rare, although pelvic and/or para-aortic lymph nodes can be involved in this process [13, 14].

Omentum as a visceral WAT depot. To better understand what lures cancer cells to the omentum we shall first review its structure. The peritoneum is a continuous membrane sheet lining the peritoneal cavity [15]. The omentum is a visceral fold of the peritoneum subdivided into greater and lesser components. The lesser omentum extends from the smaller curvature of the stomach to the liver. The greater omentum is a fatty pad that extends from the large curvature of the stomach and, like an "apron," and covers the majority of the abdominal organs converging into parietal peritoneum. This organ is made of two types of tissues. First is a highly vascularized connective tissue rich in white adipocytes and covered by a mesothelial cell layer that rests on a basement membrane, except where structures known as milky spots are located [15]. The other tissue type is a fenestrated, membranous and translucent layer composed of two mesothelial cell layers wrapping collagen fibers and fibroblast-like cells and not resting on basement membrane [15]. The main functions of the omentum as an organ are to store lipids, pool immune cells, adhere to peritoneum to localize inflammation [16, 17], regulate fluid exchange in the peritoneal cavity, and supply angiogenic and neurogenic factors [18, 19].

Omentum is one of the six visceral white adipose tissue (WAT) depots: omental, mesenteric, perirenal, gonadal, epicardial and retroperitoneal, whose developmental origin is a subject of an ongoing debate [20] [21]. Visceral WAT forms shortly after birth following prenatal development of subcutaneous WAT [22]. All six 
visceral depots derive from progenitors positive for Wilms' tumour gene (Wt1) [20]. Expression of Wt1 is specific for visceral WAT and does not trace to progenitors of subcutaneous WAT and BAT [20]. The Wt1positive mesothelium, a major source of visceral WAT, is the key characteristic differentiating visceral fat depots from subcutaneous fat [20, 23-25]. There is heterogeneity among the various visceral depots with respect to Wt1 expression, with most of the epidymal but only a portion of retroperitoneal WAT arising from Wt1-positive cells. This notion of heterogeneity is further supported by the fact that a significant portion of interscapular (iWAT) and retroperitoneal WAT (rWAT), but not epidymal fat arise from Myf5- positive precursors of brown adipose tissue (BAT) [21].

Omentum as a site of metastasis from ovarian cancer. With $80 \%$ of all serous ovarian carcinomas metastasizing to omentum, this organ appears to act as a very specific target for this type of tumor [11, 26]. Omentum is essentially a large fat pad and an endocrine tissue that can store lipids and serve as a potential source of energy for metastatic tumor cells [27]. An experimental mouse model mimicking ovarian cancer metastasis by intraperitoneal injection of tumor cells revealed that ovarian cancer cells have high propensity to seed and proliferate in the omentum [11]. High rate of homing toward the adipocytes in this model was attributed to a variety of factors, such as IL-8, IL-6, monocyte chemoattractant protein-1 (MCP-1), and adiponectin, secreted by omental adipocytes. Omental fat cells were also shown to activate pro-survival pathways, p38 and stat3, in the ovarian cancer cells, indicating the potential importance of an adipocyte-rich environment for homing and growth of tumor cells in the omentum.

Apart from chemical signaling towards the tumor cells, fat cells are also known to affect cancer cell growth and behavior through lipid-sharing. Specifically, in vitro co-culture of ovarian cancer cells with adipocytes was shown to result in transfer and accumulation of lipid droplets in the tumor cells [11]. This observation was in line with the observed presence of lipid droplets in ovarian cancer cells bordering adipocytes in the human tissue. Importantly, this acquisition of adipocyte-supplied lipids appeared to be depot-specific with most accumulation occurring upon co-culture with omental and peritoneal adipocytes compared to co-culture with subcutaneous and bowel mesenteric adipocytes [11]. The lipid transfer from adipocytes induced $\beta$ oxidation in tumor cells and enhanced their proliferation in vitro [11]. Reciprocally, cancer cells affected metabolism in adipocytes by inducing hydrolysis of triglycerides stored in adipocyte lipid droplets into free fatty acids (FFA) and glycerol [11]. Besides increased secretion of FFA and glycerol, activation of hormonesensitive lipase (HSL), an enzyme central for lipolysis, and overexpression of perilipin A, a protein coating lipid droplets and activation of which is necessary for induced lipolysis [28], were detected [11]. Essentially, it appears that cancer cells forced adipocytes to "give up" their lipids, which ultimately translated into increased tumor burden. This process would eventually lead to transformation of omentum from a fat pad into a solid tumor with few remaining adipocytes, a process often referred to as "omental caking." These observed molecular and histological changes upon adipocyte-tumor cell interactions cultivated the idea that cancer cells "consume" the energy-rich lipids necessary for their survival and progression [29]. 
Omental adipocytes and metabolic effects on tumor cells. It appears that through paracrine secretions and the abundance of readily transferable lipids, adipocytes create a microenvironment that alters tumor metabolism and supports more aggressive phenotypes. In the majority of cancers, the rapid mode of proliferation forces tumor cells to modify their energy metabolism [30], by increasing de novo lipogenesis [31, 32]. The newly synthesized fatty acids are used for storage, membrane composition and signaling, and are central for cancer thriving. In contrast, tumors such as ovarian cancers that grow in adipose-rich microenvironments, have unconventional metabolism characterized by reduced lipogenesis and increased rates of $\beta$-oxidation [11]. These observations are in line with other studies demonstrating that exogenous lipids sustain cancer cell survival when de novo lipogenesis is inhibited [33, 34]. It appears increasingly clear that instead of "going through the trouble" of making their own fuel in order to proliferate, tumor cells growing in lipid-rich adipose environments, take advantage of having these fuel molecules catered to them [27, 35]. Thus a ready source of energy may be a key reason behind their aggressive phenotype. It is also noteworthy, that although not directly demonstrated in a context of omental metastases, lipids have been shown to enhance the Warburg Effect in tumor cells [32, 36-39]. Since omental adipocytes are capable of inducing lipolysis in tumor cells [11], this lipolysis-generated glycerol has a potential to feed into the glycolytic pathway [40-42]. This could offer an additional mechanism for enhanced tumor growth and metabolic adaptation in the metastatic niche.

Supporting adipocyte involvement in modulating tumor metabolism and progression was a discovery of significant overexpression of Fatty Acid-Binding Protein 4 (FABP4) (or aP2 protein) in omental metastases from ovarian cancer, particularly at the tumor-adipocyte interface [11]. This was the first demonstration that this lipid chaperone, originally discovered in adipocytes and whose expression increases in response to fatty acid uptake and lipolytic stimulation [43-45], gets upregulated in tumor cells exposed to adipocyte-derived lipids. Lipid exposure and cholesterol accumulation are known to induce FABP4 expression in other cell types, such as macrophages, where this chaperone contributes to foam cell formation and atherosclerotic plaque instability $[43,46,47]$. Interestingly, FABP4 is also present in endothelial cells, where it appears to regulate cell proliferation [48] and its high expression in endothelial glioblastoma cells has been linked to the robust angiogenesis associated with this disease [49]. Endothelial expression of FABP4 in adipocyte-rich environments such as omentum could have a potential role in growth and progression of metastatic ovarian cancers. Indeed, reduced tumor burden and lower metastatic potential in FABP4-deficient mice was found to be associated with inhibitory effects on tumor vasculature [11]. These findings stress the importance of the adipocyte-rich tumor microenvironment and both tumor- and host-derived FABP4 in metastatic development and progression and call for further investigations.

Evidence of altered metabolic phenotype in clinical samples. To better appreciate the relevance of in vitro and in vivo animal studies we performed Oncomine analyses and compared mRNA expression of genes linked to lipid metabolism in primary and metastatic ovarian cancers. A significant upregulation of genes encoding for FABP4 and CD36 [fatty acid translocase (FAT)], proteins involved in membrane transfer of fatty acids [43, 50], 
was revealed in metastatic ovarian cancer when compared to primary tumors and confirmed in all four available datasets (Table 1). The changes in expression of specific isomers of Fatty Acid Transport Proteins (FATP1-O), which are known to regulate long-chain and very long-chain fatty acid uptake alongside CD36 [50, 51] were not consistently significant across the analyzed datasets (data not shown). Both CD36 and FATP are known to be modulated by the microenvironment, particularly in obesity, and have been shown to synergistically enhance fatty acid uptake, although in some models CD36 was demonstrated to be far more effective than FATPs [50, 52]. The functional differences between CD36 and FATPs, especially in a context of tumor metabolism are not known and need to be explored.

In addition to fatty acid transport genes we also analyzed the expression data for genes involved in lipogenesis (i.e., Fatty Acid Synthase, FASN) and lipolysis (i.e., HSL, and perilipin 2). Only modest changes in FASN levels were detected (Table 1), likely because in adipocyte-rich microenvironments like omentum, tumor cells rely more on lipid uptake from adipocytes than their own lipogenesis. The changes in lipolysis genes were also moderate. It is reasonable to assume that expression of FABP4 and CD36, proteins facilitating transport of fatty acids, were increased in both the cancer cells and adipocytes and thus easier to detect; whereas lipolysis occurred predominantly in adipocytes and depending on the stage of the tumor, the observed changes in expression might have been too modest to detect. Expression of these genes was also likely affected by the tumor heterogeneity. One noteworthy caveat of the abovementioned analyses is that the available datasets do not distinguish omentum from other potential metastatic sites. However, the fact that the observed differences in expression between primary and metastatic sites were reproducible across several datasets speaks to potential involvement of lipid transport and metabolism in metastatic progression. Apparent differences in the lipidome between subcutaneous and omental fat depots as well as tumors in patients with malignant or benign ovarian or endometrial tumors have been previously shown in a small subset of Israeli patients [53]. Significantly lower concentrations of linoleic acid (LA), a polyunsaturated fatty acid (PUFA) were shown in both fat depots in cancer patients as compared to healthy controls. Moreover, the malignant tumors appeared to have a significantly lower saturated-to-unsaturated fatty acid ratio compared to the benign tumors, suggesting that LA is mobilized from both WAT depots to be utilized by the tumors resulting in overall desaturation of the cancer. This potential link between fatty acid metabolism and ovarian cancer progression is an understudied concept that warrants further investigation.

Immune microenvironment in adipocyte-driven omental metastasis. Closer histological investigation of the omental metastases led to the idea that adipocytes might not be the only incentive that attracts cancer cells to the omentum [29]. Extensive vascular network of omentum converges in some areas into capillary beds comingled with aggregates of immune cells (macrophages, mast cells, B lymphocytes, and T lymphocytes) and stromal cells forming 'milky spots' [54, 55]. Characteristically, milky spots are reminiscent of secondary lymphoid structures and are important representatives of the immune system in peritoneal cavity $[56,57]$. Initially viewed as defense structures against bacterial antigens [58-60], these highly vascularized areas have since been implicated as preferential site for adhesion and proliferation of disseminated tumor cells 
of ovarian and colorectal origin [10, 61-66]. For tumors such as ovarian cancers, in which metastases occur primarily by direct seeding rather than through circulation, milky spots allow for rapid and selective attachment and provide an environment suitable for tumor growth and survival [10]

The initial tumor cell adhesion to the milky spots induces the influx of macrophages, which correlates with generation of new milky spots around tumor cell concentration [64, 66]. Studies utilizing a variety of immunodeficient strains of mice - Igh6, Nude, Rag1, and BN XID lacking functional B-cells, T-cells, T- and B, or T-, B- and NK-cells respectively, but having intact macrophages - show that compromised B-, T- or NKcell-mediated immunity does not affect abundance of milky spots or homing of tumor cells to these structures [29]. The depletion of peritoneal macrophages, on the other hand, inhibits the metastatic potential of ovarian cancer potentially by affecting the expression of stromal VEGF [67]. Interestingly, among a variety of known peritoneal adipose depots that include omental, mesentery, uterine, gonadal and splenoportal - milky spots are only found in omental and splenoportal fat pads [29, 68]. In line with these findings, the i.p. injection of four different ovarian cancer cell lines into mice resulted in cancerous lesions forming predominantly in omental and splenoportal fat depots, as opposed to other depots, validating the importance of milky spots in tumor homing [29]. This significantly increased migration of ovarian cells was attributed to factors secreted by omental and splenoportal fat depots [29]. It appears that interaction of adipocytes with peritoneal macrophages might be important for the homing of the disseminating ovarian cancer cells and progression of metastasis. It has been demonstrated that adipocyte-supplied PUFAs serve as ligands for transcription factor peroxisome proliferatoractivated receptor $\beta / \delta(\mathrm{PPAR} \beta / \delta)$ in macrophages, causing their polarization into tumor-associated phenotype (known as tumor-associated macrophage; TAM) [69]. Accordingly, TAMs isolated from serous ascites of ovarian cancer patients contain lipid droplets with high composition of LA, and lower but high levels of AA and docasahexaenoic acid (DHA) polyunsaturated fatty acids (PUFAs) [69]. This accumulation of fatty acids by macrophages leads to transcriptional deregulation and activation of protumorigenic phenotype.

Adipocyte-induced angiogenesis. Beside the aggregates of immune cells, milky spots are also characterized by microvascular beds and are areas of active angiogenesis $[10,65]$, a known contributor to tumor progression [55, 70]. High levels of neovascularization in milky spots have been attributed to secretion of vascular endothelial growth factor A (VEGF-A) predominantly by mesothelial cells of the omentum and to a lesser degree by omental macrophages [10]. Isolated and in situ omental adipocytes were shown to secrete VEGF $[10,71]$ and express additional angiogenesis-associated factors and receptors, such as CD105 [10] and VEGFR3 [65]. Notably, the expression of VEGF appears to be induced when omental adipocytes undergo hypoxia [71], which is in line with the evidence of clearly hypoxic phenotype in a portion of mesothelial cells and macrophages isolated from murine omentum [10]. Both hypoxia, and hypoxia-induced neovascularization have been linked to invasiveness, survival and chemoresistance of many cancers including ovarian tumors [72, 73]. A specific role for adipocytes and adipocyte-derived fatty acids in neovascularization.is further suggested by the lower levels of angiogenesis associated with reduced tumor burden in mice deficient for FABP4 [11]. These observations are underscored by our Oncomine analyses, which reveal that in addition to upregulation of 
genes encoding $F A B P 4$ and $C D 36$, metastatic ovarian tumors, representing primarily omental metastases, exhibit significantly increased expression of angiogenic genes (VEGFR1,VEGFR2, CD31 and CD34) compared to primary tumors (Table 2). This implies, that although extensive vasculature of the omentum is probably sufficient for the initial tumor colonization and survival, angiogenic factors released by the tumor as well as the microenvironment in response to tumor presence further enhance neovascular growth to meet demands of increased tumor burden [65].

Taken together, it appears that upon dissemination, cancer cells are drawn to the milky spots, as sites of high neovascularization and immune cell presence conducive to initial tumor colonization and survival. Once adhered and viable, the abundance of energy from adipocytes allows for further tumor expansion. This "parasitic" mode of survival of cancer cells reduces the number of adipocytes as tumor progresses [10, 29] and naturally hypoxic omental cells drive the hypoxia-mediated angiogenesis [10]. Hypoxia worsens as tumor burden increases, which further enhances angiogenesis and advances tumor progression even when fat depots are depleted.

\section{Metastatic Microenvironment Generated by Bone Marrow Adipose Tissue (MAT).}

National Cancer Institute lists bone as a main site of metastases from prostate, breast, lung, thyroid, melanoma, kidney, bladder and uterine cancers [9]. Although bone contains few adipocytes at birth, the abundance of marrow fat cells increases dramatically as we age [22]. Other factors, including metabolic imbalance associated with obesity, calorie restriction and anorexia nervosa, administration of select diabetes treatment drugs, such as members of Thiazolidinedione (TZD) class, as well as chemotherapy and radiotherapy represent additional contributors to increased bone marrow adiposity [22,74,75]. This is of importance, as in parallel, the factors contributing to the development of MAT are also linked to the poor prognosis for tumors with high affinity for bone, such as prostate [76-78] and breast cancers [79].

Defining MAT and its origin. In view of recent findings, the ontogeny of bone marrow adiposity remains unclear. A recent study based on genome sequencing of subcutaneous WAT from patients who underwent allogenic transplantation with bone marrow or peripheral blood stem cells revealed evidence of donor genome in recipient WAT [80]. This suggested the existence of mobile bone marrow-derived hematopoietic precursors of WAT, although whether the same precursors can give rise to MAT is not clear. Nevertheless, these findings put in question the previous notion of morphological structural differences in the origin of these two depots and introduced the idea that WAT and MAT might be deriving from same progenitor populations [81]. The additional evidence for common origin of MAT and WAT came from the observation that mesenchymal progenitors of bone marrow adipocytes and approximately half of MAT adipocytes can be traced by Platelet Derived Growth Factor Receptor-alpha (PdgfR $\alpha$ ), the same surface marker as progenitors of WAT [22]. At the same time these data also suggested that two distinct types of MAT precursors may exist, one 
common to MAT and WAT and one that is MAT-specific. Accordingly, only MAT and not WAT adipocytes express Osterix $1\left(O_{s x l}\right)$ [22] a transcription factor involved in osteoblast differentiation [82, 83]. This not only speaks to the mesenchymal origin of at least a portion of marrow adipocytes, but indicates there are distinct differences between some populations of progenitors of MAT and WAT. As understanding of the origin of MAT is clearly an evolving field, the question of progenitors of different fat depots remains to be clarified.

Additional controversy related to origin of MAT comes from the fact that MAT adipocytes and osteoblasts were long thought to share the same mesenchymal stem cell precursor [84]; however, newly emerging findings now show that bone marrow has two mesenchymal progenitor populations: one giving rise to osteoblasts, stromal cells and adipocyte lineages $[22,85,86]$ and the other differentiating to all mesenchymal lineages but adipocytes [22, 87]. Numerous factors drive osteoblast differentiation: Runt-related transcription factor 2, Runx2, core binding factor $\beta, \operatorname{Cbf} \beta$, Osx, activating transcription factor 4, ATF4, and transcriptional coactivator with a PDZ-binding motif, TAZ [88]. Osteoblasts are also sensitive to hormonal regulation, and since they express hormone receptors such as androgen receptors, estrogen receptor-alpha and -beta [89], age-related hormonal decline [90] or androgen deprivation therapy [91] may contribute to bone loss by affecting osteoblast differentiation. There are also many transcription factors that can influence adipocyte differentiation, with peroxisome proliferatior-activated receptor gamma (PPAR $\gamma)$ and CCAAT/enhancer binding protein a (C/EBPa) considered the master regulators [88]. Expectedly, exogenous agonists of PPAR $\gamma$ stimulate adipogenesis, with some, depending on the nature and affinity of the ligand, inhibiting bone formation by suppressing osteogenesis- driving transcription factors [92]. One example is Rosiglitazone, a potent ligand of PPAR $\gamma$, which promotes bone loss and development of marrow adipocytes [93-96]. A significant plasticity between osteogenesis and adipogenesis pathways is thought to exist in adult bone allowing certain factors to shift the balance in either direction $[88,97,98]$. Specifically, Wnt signaling was identified as a cue for stimulation of osteoblast differentiation at the expense of adipogenesis through inhibition of PPAR $\gamma$ and C/EBP $\alpha$ [99, 100]. Regulation of Wnt is thought to be one of the key contributors to the inverse relationship between fat and bone formation [99]. However, the possibility that different postnatal lineages for adipocytes and osteoblasts exist may explain the lack of correlation between increased MAT and decreased bone density in various strains of mice $[22,101]$ and in fatty bones induced by high fat diet [102]. Moreover, pharmacological inhibition of marrow adipogenesis with bisphenol-A-diglycidyl ether (BADGE), or loss of function mutations in kit receptor resulting in the absence of marrow adipose tissue in mice do not inhibit bone loss due to type 1 diabetes or ovariectomy, respectively, thus further challenging the existence of a causal link between augmented marrow adipocytes and osteopenia [103, 104].

Although adipocytes are scarce in the bone microenvironment at birth, adipogenesis causes progressive replacement of the red marrow in the distal skeletal regions with adipocyte-rich yellow marrow (reviewed in [88]). The red marrow, which remains centralized to the axial skeleton, continues to house the majority of the hematopoietic cells, but can still retain a large proportion of adipocytes. The localization in the skeleton is what appears to be the determining factor in differential development and regulation of MAT [101]. Specifically, 
MAT adipocytes that are interspersed with the red, hematopoietic marrow ('proximal' regulated MAT, rMAT) appear to be different from those that make up the adipocyte-rich, yellow marrow ('distal' constitutive MAT, cMAT). This is in line with early studies, which showed distinctly different lipid composition between adipocytes localized to red as opposed to yellow marrow [105]. Although there is still a lot to be uncovered about specific characteristics of rMAT and cMAT, we know so far that the rMAT adipocytes preferentially develop within the red marrow throughout life, and can be depleted with 21-day cold exposure [101]. They are also smaller in size, contain more saturated lipids, express lower levels of Cebpa and Cebpb, and are lost in a PTRF (Polymerase I and Transcript Release Factor) knock-out mouse model of congenital generalized lipodystrophy (CGL) [101]. Conversely, cMAT adipocytes develop shortly after birth and do not respond to 21day cold exposure. They are larger, contain more unsaturated lipids relative to total lipid content, have elevated Cebpa and Cebpb, and are preserved in the PTRF knock-out mouse [101]. Degree of lipid saturation and expression of adipocyte genes in rMAT are similar to WAT. Thus cMAT has increased lipid unsaturation and elevated expression of these genes relative to both rMAT and WAT depots. The important question that warrants further investigation is how these differences in rMAT and cMAT affect attraction and progression of metastatic cells in bone.

Role of pro-angiogenic factors in homing of cancer cells to the bone. Although many advances have been made in efforts to understand how the tumor microenvironment influences progression of skeletal metastases, deciphering what attracts circulating tumor cells to bone remains to be elucidated. Studies on bone colonization by the epithelial tumors, such as prostate and breast cancers, suggest that to initiate the metastatic cascade, primary tumor cells must undergo an epithelial-to-mesenchymal transformation (EMT), [106]. The mesenchymal phenotype includes invasive behavior that allows cells to penetrate the surrounding stroma of the primary site, enter circulation and thus reach the bone. According to Stephen Paget's "seed and soil hypothesis", cancer cells preferentially metastasize to specific organs in a "pre-determined" fashion [107]. In line with this original hypothesis, primary tumor cells have been shown to be "primed" for metastasis by hematopoietic progenitor cells (HPCs) expressing vascular endothelial growth factor receptor 1 (VEGFR1) [108]. These HPCs reside within specified niches of the bone marrow and are recruited to the primary site to drive angiogenesis and tumor growth. Following interaction with primary tumor cells, the clusters of VEGFR1+ HPCs cells home to the metastatic site and generate a 'pre-metastatic niche' that attracts disseminated tumor cells (DTCs) [109].

Once in the bone, DTCs adhere to the endothelium of the sinusoidal blood vessels throughout bone marrow [106]. In fact, initial micrometastatic formations in the bone marrow are observed at the perivascular areas of the sinusoidal vessels [110]. Our own Oncomine analysis of mRNA levels of pro-angiogenic genes in prostate cancer patients data revealed significant upregulation of Flt1 gene in metastatic compared to the primary prostate cancer in three out of ten studies (Table 3). Other angiogenic genes induced in metastatic prostate cancer were CD31 (in 2/3 datasets), CD34 (in 2/11 datasets), and VEGFR3 (in 5/9 datasets) (Table 3). Additional evidence that marrow adipocytes contribute to the upregulation of angiogenesis-supporting factors 
comes from our own studies in metastatic prostate tumor cells in vitro and in vivo [111]. Specifically, we have shown that exposure of prostate cancer cells to marrow adipocytes induces expression of pro-angiogenic VEGF as well as genes coding for pro-inflammatory cytokines, CCL20, IL-1 $\alpha$ and IL-1 $\beta$ [111]. Our data also revealed an upregulation of hypoxia inducible factor-1alpha (HIF-1 $\alpha$ ) [111], a known regulator of angiogenesis, and a key driver of tumorigenesis [112]. Collectively, neovascularization is an important factor in tumor colonization and growth in metastatic sites such as bone, and there is growing evidence that MAT via its effect on cancer cells might be promoting angiogenesis-mediated progression of skeletal metastases.

\section{Cytokine/chemokine signaling and inflammatory microenvironment in metastatic disease in bone.}

Cancer homing to the bone has been extensively linked to specific chemokine signaling pathways, particularly those driven by CXCL12/CXCR4 and CXCL16/CXCR6 chemokine/receptor axes [113-115]. Tumor cells expressing CXCR4 receptor migrate toward endothelial cells and osteoblasts, which secrete its ligand, CXCL12. Interestingly, although not investigated in a context of MAT, CXCL12 has been shown to be secreted by WAT adipocytes and to be involved in the recruitment of macrophages [116]. Upon arrival in bone, many DTCs, most of which have escaped chemotherapy, stay dormant $[117,118]$. Factors such as bone remodeling [119], hypoxia [120] and cytokines like Parathyroid Hormone-related Protein (PTHrP), endothelin, Transforming Growth Factor beta (TGF- $\beta$ ), Platelet-derived Growth Factor (PDGF), Insulin-like Growth Factor 1(IGF1) are known to influence metastatic progression, potentially by allowing tumor cells to escape dormancy [121]. One important factor credited with the ability to keep metastatic breast cancer cells in dormant state is Thrombospondin-1-(TSP-1), an anti-angiogenic molecule expressed by endothelial cells of bone marrow microvasculature and shown to act as a tumor suppressor [122]. The deposits of TSP-1 disappear around sprouting tips of microvascular endothelium and this coincides with a high concentration of pro-tumorigenic factors, such as active TGF- $\beta 1$ and periostin around neovascular tips [122]. Therefore, it appears that established microvessels inhibit metastatic potential of DTCs, whereas, in contrast, the neovascular tips promote tumor cell growth [122]. Surprisingly, bone marrow derived- $\mathrm{CD} 11 \mathrm{~b}^{+} \mathrm{Gr}^{+}$cells and subcutaneous and visceral adipocytes were shown to express anti-angiogenic TSP-1 and its overexpression positively correlated with obesity [123-125]. To add to the confusion, the expression of TSP-1 by adipocytes was shown to be significantly reduced by pioglitazone, a PPAR- $\gamma$ agonist with insulin sensitizing activities [123]. On the other hand, there is also evidence to suggest that obesity-associated induced expression of TSP-1 may mediate recruitment of macrophages to adipose tissue and release of pro-inflammatory cytokines contributing to obesityaccompanied low-grade systemic inflammation [126]. TSP-1 increases expression of its receptor CD36 in bone marrow-derived macrophages[127], and activates macrophages via Toll like receptor 4 (TLR4) [128]. Therefore, aside from the earlier mentioned function in facilitating lipid transport, CD36 also appears to play a role in inflammation and angiogenesis[127]. We have previously shown that culturing prostate cancer cells in bone marrow-derived adipocyte conditioned media results in mRNA overexpression of CD36 [111]. Furthermore, our Oncomine analysis revealed significant overexpression of CD36 in metastatic prostate cancer when compared to primary tumor in four out of ten available prostate cancer databases (Table 4). Although adipocytes clearly modulate tumor microenvironment to support aggressive phenotype of skeletal metastasis, 
the relationship between marrow adiposity and tumor cell escape from dormancy is not straightforward and remains to be further investigated.

Role of adipogenesis in bone remodeling-mediated metastatic progression. It is becoming increasingly clear that the relationship between adipocytes and bone is complex, with some evidence of reciprocal association between increased adiposity and inhibition of osteoblast viability and function [129-132] and other studies revealing no apparent link between adipocyte numbers and bone density [103, 104]. It appears, however, that marrow adiposity may have definite promoting effects on tumor-driven osteolysis of the bone. Accelerated bone remodeling is one of the key factors associated with homing of tumor cells to the bone [133, 134]. Experimental treatment with calciotropic hormone [133] or estrogen and androgen ablation [90] increases bone turnover, which in turn promotes tumor cell growth and occurrences of skeletal metastases [91, 119]. We have recently shown that bone marrow-derived adipocytes accelerate bone degradation by promoting osteoclastogenesis and augmenting osteoclast-specific expression of cathepsin K, MMP9 and calcineurin, proteins involved in bone remodeling [135]. This process is at least partially mediated by adipocytic secretion of pro-inflammatory chemokines of CXC family, CXCL1 and CXCL2, whose levels are dramatically increased upon adipocyte interaction with PC3 and ARCAP(M) prostate carcinoma cells in bone. This is of importance in a context of metastatic tumor growth, as CXCL1 and CXCL2 are chemoattractants for macrophages,

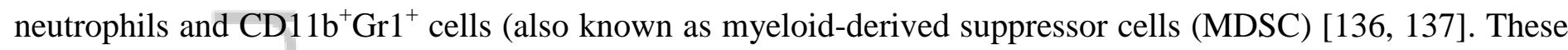
immune cells express CXCR2 receptors and are capable of modulating tumor microenvironment and affecting progression by stimulating angiogenesis [138, 139], suppressing anti-tumor immune responses [140] and promoting chemoresistance [137]. This suggests the importance of bone marrow adiposity in bone remodeling associated with cancer-induced bone disease and opens avenues for further investigations.

Bisphosphonates are a class of drugs known primarily for their effects on osteoclast differentiation and survival [141], but are gaining recent attention with respect of their activity towards other cell types in bone [131, 142144]. Of particular note is a recent study demonstrating that a single dose of bisphosphonate Zoledronic acid (ZOL) prevents ovariectomy-induced marrow adiposity in rats [131]. This potential effect on adipocyte pool in bone could have clinical implications as ZOL has been administered to prostate [91, 145] and breast cancer patients [119] for the treatment and prevention of skeletal-related events and showed some promise based on the randomized study in castrate resistant prostate patients with bone metastases [146]. Unfortunately, a recent study revealed that administration of ZOL, within six months of androgen deprivation therapy to castration sensitive men with bone metastases does not reduce risks for skeletal-related events [147]. More positive results came from preclinical studies in mice bearing androgen receptor negative (PC3) tumors, where ZOL administration at the time of castration was shown to inhibit castration-triggered metastatic growth [91]. Analogous to castration in males, ovariectomy in female mice was shown to induce bone loss and increase growth of breast cancer cells in bone, processes, which were inhibited by ZOL treatment [91, 119]. These observations are in line with the results of recent epidemiological study showing that use of bisphosphonates can reduce the rate of skeletal-related events only in postmenopausal women [148], supporting the idea that 
bone remodeling and accumulation of MAT in response to hormonal deprivation may be playing an important role in activation of DTCs.

Role of MAT in tumor metabolism. The important evidence that marrow adipocytes may have significant impact on progression of skeletal metastases came from our studies utilizing diet-induced marrow adiposity model [111]. Intratibial injections of metastatic prostate cancer cell line (PC3) into high fat dietinduced fatty bones resulted in accelerated intraosseous tumor growth [111]. Exposure of prostate cancer cells to marrow adipocytes in vitro led to a significant accumulation of lipid droplets in the tumor cells, a process that was accompanied by overexpression of three major regulators of lipid trafficking, FABP4, Perilipin 2 and CD36. In parallel, overexpression of FABP4 was also observed in the bone metastatic lesions as compared to benign and primary prostate cancer tissues [111]. Co-culture of marrow adipocytes with prostate cancer cells turned out to be detrimental to adipocytes as observed by the loss of lipid droplets and cell shrinkage. We showed, that adipocytes promote cancer cell proliferation and induce invasive behavior in tumor cells, a process mediated, at least partially, by IL-1 $\beta$ - and FABP4-dependent mechanisms [111]. These findings are in line with our Oncomine data, which show that metastatic prostate cancers exhibit highly increased expression of $F A B P 4$ (in 8 out of 12 datasets) and CD36 (in 4/10 datasets) compared to primary tumors (Table 4). Although not consistently altered across all prostate cancer data sets, several of the FATP isomers are also significantly upregulated in metastatic tissues. These data are in contrast to no observed significant changes in FATP transporters in omental metastases, which suggests there might be depot-specific differences in fatty acid transport mechanisms between the two sites that differentially affect metastatic progression. Other noteworthy changes between primary and metastatic tumors include the increased levels of lipolysis-associated genes, $H S L$ (in 2 out of 4 datasets), and perilipin 2 (3/12 datasets), as well as lipogenesis-associated FASN (in 7/12 datasets) results further linking the presence of adipocytes in the microenvironment of cancer cells with altered metabolism.

The role of fatty acyl lipidome. To better understand the role of MAT in tumorigenesis it is important to evaluate its lipidome. Analysis of normal human bone marrow fatty acid composition showed a wide range of saturated and unsaturated fatty acids [149]. Oleic, palmitic and omega-6 polyunsaturated acid (PUFA), linoleic acids (LA), are just a few examples of the most abundantly available fatty acids in the bone marrow [149]. Arachidonic acid (AA) [55], was found less abundant in bone marrow stroma cells, marrow plasma [150] and in bone marrow mononuclear cells [151] where it was shown to be incorporated into triglycerides and phospholipids. Availability of fatty acids in the tumor microenvironment has a potential to affect tumor cell behavior and growth. Accordingly, in vitro studies have shown that PC3 prostate carcinoma cells migrate toward bone marrow stromal cells and bone marrow derived adipocytes [152, 153]. The detailed translocation of lipids from human bone marrow derived-adipocytes to prostate cancer cells was further revealed by Fourier Transform Infrared (FTIR) microspectroscopy [154]. LA and AA were shown to enhance proliferation and cellular invasion of prostate cancer cells, potentially as a result of lipid transfer [155]. Direct treatment of PC3 cells with AA showed activation of phosphatidylinositol 3-kinase (PI3K)/AkT and NF-kB signaling pathways 
leading to rise in gene expression of cyclooxygenase-2 (COX-2), IL-8, IL-1 $\beta, I L-6, T N F-\alpha, L T A, C X C L 1$, PPAR , GM-CSF, NFkB2, IkB $\alpha$ and ICAM-1 (CD54) [156]. The uptake of AA by PC3 cells was shown to induce proliferation [156] and promote invasion, a process inhibited by blocking synthesis of prostaglandin E2 $\left(\mathrm{PGE}_{2}\right)$ with omega-3 ( $\left.\omega-3 / \mathrm{n}-3\right)$ PUFAs [152]. $\mathrm{PGE}_{2}$ is a major COX-2 metabolite reported to induce cellular proliferation, increase expression of COX-2, and stimulate endogenous synthesis of $\mathrm{PGE}_{2}$ [157]. As an immunoregulator, $\mathrm{PGE}_{2}$, was reported to play a role in cancer stem cell repopulation and chemoresistance, further implicating AA metabolism in prostate cancer progression [158]. Notably, metabolic processing of AA by lipoxygenase (LOX) is known to result in the production of pro-tumorigenic metabolites, and 5-LOX metabolites of n-6 PUFA, 5(S)-HETE and 5-oxoETE, have been shown to inhibit apoptosis [159]. Furthermore, overexpression of 12-LOX and the augmented levels of its metabolite 12(S)-HETE correlate with enhanced angiogenic potential and increased tumor burden [160, 161]. Although little is known about specific involvement of LA and AA metabolites in tumor progression in bone, the abovementioned studies suggest that bone-marrow adipocyte-derived n-6 PUFAs in MAT may serve important role in driving metastatic bone disease, which warrants further investigation.

It is important to note, that despite its negative publicity, omega- 6 fatty acids remain important lipid molecules and their role in cancer should be viewed in a ratio to $\omega$-3. Omega-3 PUFAs are represented by $\alpha$-linolenic acid $(\alpha$-LNA, n-3) and its long-chain metabolites, eicosapentaenoic acid (EPA, n-3) and docasahexaenoic acid (DHA, n-3), dietary consumption of which is demonstrated to decrease the risk of prostate cancer [162]. It has been suggested that $\mathrm{n}-3$ competes with $\mathrm{n}-6$ for $\Delta 4$ and $\Delta 6$-desaturases (reviewed in [163]). With $\mathrm{n}-3$ having a higher affinity for these enzymes, increased consumption of omega-3 PUFA results in decreased conversion of LA into AA and consequently its metabolites [163]. As a result, the cancer chemopreventive role of $n-3$ is usually described as its ratio to n-6 PUFAs [163]. As expected, the level of $\mathrm{PGE}_{2}$, a derivative of AA, in rat bone marrow was significantly increased in rats on high ratio of $n-6 / n-3$ fatty acid diet [164]. Furthermore, the analysis of fatty acids in prostatic tissues showed significantly higher n-6/n-3 (shown as lower n-3/n-6) ratio in cancer samples compared to benign hyperplasia [165]. Based on these findings it appears that effects of marrow adiposity on tumor cells might be dependent on the individual lipidome.

\section{Conclusions:}

A key characteristic of a metastatic tumor is its dependence on the environment that surrounds it. Colonization and growth at the secondary site is a complex process involving reciprocal interactions between the tumor cells and the host microenvironment. Visceral WAT and MAT represent two distinct metastatic niches that have a common characteristic: they are adipocyte-rich depots, that promote tumor progression by supplying lipids to disseminated cancer cells, stimulating growth factor signaling, modulating cancer cell metabolism and stemmness and priming the microenvironment for metastatic growth. Both WAT and MAT adipocytes evoke immunoregulatory effects on the environment by influencing the behavior of immune cells and modulating the 
release of pro-inflammatory cytokines and lipid metabolites. They also appear to play a role in angiogenesis via direct release of pro-angiogenic factors or stimulation of their secretion by neighboring cells, including the tumor cells. It is those effects on the host cells, in combination with direct impact on tumor cells via altered fatty acid metabolism, that provide an environment conducive to tumor adaptation and survival (Figure 1). Little is known on whether heterogeneity of WAT and MAT has any effect on colonization and growth of tumor cells that homed to that site. There is evidence to suggest that more than one population of WAT and MAT adipocytes exist, some sharing common progenitors between the two fat depots and some of the origin that is distinct to a specific site. Time and additional research efforts will reveal whether the metabolic symbiosis between adipocytes and tumor cells at the metastatic site is driven by a specific population of adipocytes, and whether this opens avenues for therapeutic intervention.

\section{FIGURE LEGENDS}

Figure 1. A schematic of proposed mechanisms underlying involvement of WAT and MAT in metastatic colonization and progression in omentum and bone. Omentum and bone are adipocyte-rich organs. Adipocytes in either depot have the propensity to fuel tumor growth and survival within the metastatic niche. Both depots are major sources of polyunsaturated fatty acids (PUFA), Wnt ligands, free fatty acids (FFA), cytokines IL-6 and IL-8, MCP-1, and VEGF, all of which are known contributors to tumorigenesis. The specific MAT-derived factors such as TNF- $\alpha$, IL- $\beta$, CXCL1, and CXCL2 as well as WAT-derived CXCL12, CD105, and VEGFR3, have also all been linked to metastatic disease. Tumor cells within an adipocyte-rich microenvironment have the ability to modulate adipocyte function by stimulating lipolysis and affecting secretion of pro-tumorigenic, pro-angiogenic and immunomodulatory factors. The interaction between adipocytes and tumor cells within the metastatic niche promotes metastatic progression through metabolic reprogramming or adaptation, immunomodulation, angiogenesis, EMT, and growth factor/survival pathway signaling

\section{REFERENCES:}

1. Bays, H.E., J.M. Gonzalez-Campoy, G.A. Bray, A.E. Kitabchi, D.A. Bergman, A.B. Schorr, et al., Pathogenic potential of adipose tissue and metabolic consequences of adipocyte hypertrophy and increased visceral adiposity. Expert Rev Cardiovasc Ther, 2008. 6(3): p. 343-68.

2. Wajchenberg, B.L., Subcutaneous and visceral adipose tissue: their relation to the metabolic syndrome. Endocr Rev, 2000. 21(6): p. 697-738.

3. Wozniak, S.E., L.L. Gee, M.S. Wachtel, and E.E. Frezza, Adipose tissue: the new endocrine organ? A review article. Dig Dis Sci, 2009. 54(9): p. 1847-56.

4. Trayhurn, P. and J.H. Beattie, Physiological role of adipose tissue: white adipose tissue as an endocrine and secretory organ. Proc Nutr Soc, 2001. 60(3): p. 329-39. 
5. Scherer, P.E., Adipose tissue: from lipid storage compartment to endocrine organ. Diabetes, 2006. 55(6): p. 153745.

6. Wang, P., E. Mariman, J. Renes, and J. Keijer, The secretory function of adipocytes in the physiology of white adipose tissue. J Cell Physiol, 2008. 216(1): p. 3-13.

7. Conde, J., M. Scotece, R. Gomez, V. Lopez, J.J. Gomez-Reino, F. Lago, et al., Adipokines: biofactors from white adipose tissue. A complex hub among inflammation, metabolism, and immunity. Biofactors, 2011. 37(6): p. 41320.

8. Tilg, H. and A.R. Moschen, Adipocytokines: mediators linking adipose tissue, inflammation and immunity. Nat Rev Immunol, 2006. 6(10): p. 772-83.

9. $\quad \mathrm{NCl}$, Metastatic Cancer. 2013.

10. Gerber, S.A., V.Y. Rybalko, C.E. Bigelow, A.A. Lugade, T.H. Foster, J.G. Frelinger, et al., Preferential attachment of peritoneal tumor metastases to omental immune aggregates and possible role of a unique vascular microenvironment in metastatic survival and growth. Am J Pathol, 2006. 169(5): p. 1739-52.

11. Nieman, K.M., H.A. Kenny, C.V. Penicka, A. Ladanyi, R. Buell-Gutbrod, M.R. Zillhardt, et al., Adipocytes promote ovarian cancer metastasis and provide energy for rapid tumor growth. Nat Med, 2011. 17(11): p. 1498-503.

12. He, Y., A.C. Wu, B.S. Harrington, C.M. Davies, S.J. Wallace, M.N. Adams, et al., Elevated CDCP1 predicts poor patient outcome and mediates ovarian clear cell carcinoma by promoting tumor spheroid formation, cell migration and chemoresistance. Oncogene, 2016. 35(4): p. 468-78.

13. Lengyel, E., Ovarian cancer development and metastasis. Am J Pathol, 2010. 177(3): p. 1053-64.

14. Tan, D.S., R. Agarwal, and S.B. Kaye, Mechanisms of transcoelomic metastasis in ovarian cancer. Lancet Oncol, 2006. 7(11): p. 925-34.

15. Wilkosz, S., G. Ireland, N. Khwaja, M. Walker, R. Butt, A. de Giorgio-Miller, et al., A comparative study of the structure of human and murine greater omentum. Anat Embryol (Berl), 2005. 209(3): p. 251-61.

16. Ellis, H., The aetiology of post-operative abdominal adhesions. An experimental study. Br J Surg, 1962. 50: p. 106.

17. Hall, J.C., K.A. Heel, J.M. Papadimitriou, and C. Platell, The pathobiology of peritonitis. Gastroenterology, 1998. 114(1): p. 185-96.

18. Chamorro, M., F. Carceller, C. Llanos, A. Rodriguez-Alvarino, C. Colmenero, and M. Burgueno, The effect of omental wrapping on nerve graft regeneration. Br J Plast Surg, 1993. 46(5): p. 426-9.

19. Goldsmith, H.S., Role of the omentum in the treatment of Alzheimer's disease. Neurol Res, 2001. 23(6): p. 55564.

20. Chau, Y.Y., R. Bandiera, A. Serrels, O.M. Martinez-Estrada, W. Qing, M. Lee, et al., Visceral and subcutaneous fat have different origins and evidence supports a mesothelial source. Nat Cell Biol, 2014. 16(4): p. 367-75.

21. Sanchez-Gurmaches, J., C.M. Hung, C.A. Sparks, Y. Tang, H. Li, and D.A. Guertin, PTEN loss in the Myf5 lineage redistributes body fat and reveals subsets of white adipocytes that arise from Myf5 precursors. Cell Metab, 2012. 16(3): p. 348-62.

22. Berry, R., M.S. Rodeheffer, C.J. Rosen, and M.C. Horowitz, Adipose Tissue Residing Progenitors (Adipocyte Lineage Progenitors and Adipose Derived Stem Cells (ADSC). Curr Mol Biol Rep, 2015. 1(3): p. 101-109.

23. Berry, R. and M.S. Rodeheffer, Characterization of the adipocyte cellular lineage in vivo. Nat Cell Biol, 2013. 15(3): p. 302-8.

24. Fox, C.S., J.M. Massaro, U. Hoffmann, K.M. Pou, P. Maurovich-Horvat, C.Y. Liu, et al., Abdominal visceral and subcutaneous adipose tissue compartments: association with metabolic risk factors in the Framingham Heart Study. Circulation, 2007. 116(1): p. 39-48. 
25. Liu, J., C.S. Fox, D.A. Hickson, W.D. May, K.G. Hairston, J.J. Carr, et al., Impact of abdominal visceral and subcutaneous adipose tissue on cardiometabolic risk factors: the Jackson Heart Study. J Clin Endocrinol Metab, 2010. 95(12): p. 5419-26.

26. Doig, T. and H. Monaghan, Sampling the omentum in ovarian neoplasia: when one block is enough. Int J Gynecol Cancer, 2006. 16(1): p. 36-40.

27. Nieman, K.M., I.L. Romero, B. Van Houten, and E. Lengyel, Adipose tissue and adipocytes support tumorigenesis and metastasis. Biochim Biophys Acta, 2013. 1831(10): p. 1533-41.

28. Brasaemle, D.L., V. Subramanian, A. Garcia, A. Marcinkiewicz, and A. Rothenberg, Perilipin A and the control of triacylglycerol metabolism. Mol Cell Biochem, 2009. 326(1-2): p. 15-21.

29. Clark, R., V. Krishnan, M. Schoof, I. Rodriguez, B. Theriault, M. Chekmareva, et al., Milky spots promote ovarian cancer metastatic colonization of peritoneal adipose in experimental models. Am J Pathol, 2013. 183(2): p. 57691.

30. Schulze, A. and A.L. Harris, How cancer metabolism is tuned for proliferation and vulnerable to disruption. Nature, 2012. 491(7424): p. 364-73.

31. Currie, E., A. Schulze, R. Zechner, T.C. Walther, and R.V. Farese, Jr., Cellular fatty acid metabolism and cancer. Cell Metab, 2013. 18(2): p. 153-61.

32. Baenke, F., B. Peck, H. Miess, and A. Schulze, Hooked on fat: the role of lipid synthesis in cancer metabolism and tumour development. Dis Model Mech, 2013. 6(6): p. 1353-63.

33. Ros, S., C.R. Santos, S. Moco, F. Baenke, G. Kelly, M. Howell, et al., Functional metabolic screen identifies 6phosphofructo-2-kinase/fructose-2,6-biphosphatase 4 as an important regulator of prostate cancer cell survival. Cancer Discov, 2012. 2(4): p. 328-43.

34. Daniels, V.W., K. Smans, I. Royaux, M. Chypre, J.V. Swinnen, and N. Zaidi, Cancer cells differentially activate and thrive on de novo lipid synthesis pathways in a low-lipid environment. PLoS One, 2014. 9(9): p. e106913.

35. Martinez-Outschoorn, U.E., F. Sotgia, and M.P. Lisanti, Power surge: supporting cells "fuel" cancer cell mitochondria. Cell Metab, 2012. 15(1): p. 4-5.

36. Schwartz, B. and E. Yehuda-Shnaidman, Putative role of adipose tissue in growth and metabolism of colon cancer cells. Front Oncol, 2014. 4: p. 164.

37. Watson, D.G., F. Tonelli, M. Alossaimi, L. Williamson, E. Chan, I. Gorshkova, et al., The roles of sphingosine kinases 1 and 2 in regulating the Warburg effect in prostate cancer cells. Cell Signal, 2013. 25(4): p. 1011-7.

38. Tonelli, F., M. Alossaimi, V. Natarajan, I. Gorshkova, E. Berdyshev, R. Bittman, et al., The roles of sphingosine kinase 1 and 2 in regulating the metabolome and survival of prostate cancer cells. Biomolecules, 2013. 3(2): p. 316-33.

39. Manzi, L., L. Costantini, R. Molinari, and N. Merendino, Effect of Dietary omega-3 Polyunsaturated Fatty Acid DHA on Glycolytic Enzymes and Warburg Phenotypes in Cancer. Biomed Res Int, 2015. 2015: p. 137097.

40. Vaughan, M., The production and release of glycerol by adipose tissue incubated in vitro. J Biol Chem, 1962. 237: p. 3354-8.

41. Maeda, N., T. Funahashi, and I. Shimomura, Metabolic impact of adipose and hepatic glycerol channels aquaporin 7 and aquaporin 9. Nat Clin Pract Endocrinol Metab, 2008. 4(11): p. 627-34.

42. Langin, D., Control of fatty acid and glycerol release in adipose tissue lipolysis. C R Biol, 2006. 329(8): p. 598-607; discussion 653-5.

43. Furuhashi, M. and G.S. Hotamisligil, Fatty acid-binding proteins: role in metabolic diseases and potential as drug targets. Nat Rev Drug Discov, 2008. 7(6): p. 489-503.

44. Furuhashi, M., G. Tuncman, C.Z. Gorgun, L. Makowski, G. Atsumi, E. Vaillancourt, et al., Treatment of diabetes and atherosclerosis by inhibiting fatty-acid-binding protein aP2. Nature, 2007. 447(7147): p. 959-65. 
45. Hertzel, A.V. and D.A. Bernlohr, The mammalian fatty acid-binding protein multigene family: molecular and genetic insights into function. Trends Endocrinol Metab, 2000. 11(5): p. 175-80.

46. Hardaway, A.L. and I. Podgorski, IL-1beta, RAGE and FABP4: targeting the dynamic trio in metabolic inflammation and related pathologies. Future Med Chem, 2013. 5(10): p. 1089-108.

47. Makowski, L., K.C. Brittingham, J.M. Reynolds, J. Suttles, and G.S. Hotamisligil, The fatty acid-binding protein, aP2, coordinates macrophage cholesterol trafficking and inflammatory activity. Macrophage expression of aP2 impacts peroxisome proliferator-activated receptor gamma and IkappaB kinase activities. J Biol Chem, 2005. 280(13): p. 12888-95.

48. Elmasri, H., C. Karaaslan, Y. Teper, E. Ghelfi, M. Weng, T.A. Ince, et al., Fatty acid binding protein 4 is a target of VEGF and a regulator of cell proliferation in endothelial cells. FASEB J, 2009. 23(11): p. 3865-73.

49. Cataltepe, O., M.C. Arikan, E. Ghelfi, C. Karaaslan, Y. Ozsurekci, K. Dresser, et al., Fatty acid binding protein 4 is expressed in distinct endothelial and non-endothelial cell populations in glioblastoma. Neuropathol Appl Neurobiol, 2012. 38(5): p. 400-10.

50. Balaban, S., L.S. Lee, M. Schreuder, and A.J. Hoy, Obesity and cancer progression: is there a role of fatty acid metabolism? Biomed Res Int, 2015. 2015: p. 274585.

51. Doege, H. and A. Stahl, Protein-mediated fatty acid uptake: novel insights from in vivo models. Physiology (Bethesda), 2006. 21: p. 259-68.

52. Schneider, H., S. Staudacher, M. Poppelreuther, W. Stremmel, R. Ehehalt, and J. Fullekrug, Protein mediated fatty acid uptake: synergy between CD36/FAT-facilitated transport and acyl-CoA synthetase-driven metabolism. Arch Biochem Biophys, 2014. 546: p. 8-18.

53. Yam, D., H. Ben-Hur, R. Dgani, A. Fink, A. Shani, and E.M. Berry, Subcutaneous, omentum and tumor fatty acid composition, and serum insulin status in patients with benign or cancerous ovarian or endometrial tumors. Do tumors preferentially utilize polyunsaturated fatty acids? Cancer Lett, 1997. 111(1-2): p. 179-85.

54. Shimotsuma, M., T. Takahashi, M. Kawata, and K. Dux, Cellular subsets of the milky spots in the human greater omentum. Cell Tissue Res, 1991. 264(3): p. 599-601.

55. Krist, L.F., I.L. Eestermans, J.J. Steenbergen, E.C. Hoefsmit, M.A. Cuesta, S. Meyer, et al., Cellular composition of milky spots in the human greater omentum: an immunochemical and ultrastructural study. Anat Rec, 1995. 241(2): p. 163-74.

56. Mandache, E., E. Moldoveanu, and G. Savi, The involvement of omentum and its milky spots in the dynamics of peritoneal macrophages. Morphol Embryol (Bucur), 1985. 31(2): p. 137-42.

57. Rangel-Moreno, J., J.E. Moyron-Quiroz, D.M. Carragher, K. Kusser, L. Hartson, A. Moquin, et al., Omental milky spots develop in the absence of lymphoid tissue-inducer cells and support $B$ and $T$ cell responses to peritoneal antigens. Immunity, 2009. 30(5): p. 731-43.

58. Dux, K., R.V. Rouse, and B. Kyewski, Composition of the lymphoid cell populations from omental milky spots during the immune response in C57BL/Ka mice. Eur J Immunol, 1986. 16(8): p. 1029-32.

59. Funda, D., M. Holub, and V. Sykora, Development of the cellular response in the mouse omentum after intraperitoneal immunization. APMIS, 1993. 101(12): p. 939-45.

60. Van Vugt, E., E.A. Van Rijthoven, E.W. Kamperdijk, and R.H. Beelen, Omental milky spots in the local immune response in the peritoneal cavity of rats. Anat Rec, 1996. 244(2): p. 235-45.

61. Tsujimoto, H., T. Takhashi, A. Hagiwara, M. Shimotsuma, C. Sakakura, K. Osaki, et al., Site-specific implantation in the milky spots of malignant cells in peritoneal dissemination: immunohistochemical observation in mice inoculated intraperitoneally with bromodeoxyuridine-labelled cells. Br J Cancer, 1995. 71(3): p. 468-72.

62. Hagiwara, A., T. Takahashi, K. Sawai, H. Taniguchi, M. Shimotsuma, S. Okano, et al., Milky spots as the implantation site for malignant cells in peritoneal dissemination in mice. Cancer Res, 1993. 53(3): p. 687-92. 
63. Khan, S.M., H.M. Funk, S. Thiolloy, T.L. Lotan, J. Hickson, G.S. Prins, et al., In vitro metastatic colonization of human ovarian cancer cells to the omentum. Clin Exp Metastasis, 2010. 27(3): p. 185-96.

64. Krist, L.F., M. Kerremans, D.M. Broekhuis-Fluitsma, I.L. Eestermans, S. Meyer, and R.H. Beelen, Milky spots in the greater omentum are predominant sites of local tumour cell proliferation and accumulation in the peritoneal cavity. Cancer Immunol Immunother, 1998. 47(4): p. 205-12.

65. Sorensen, E.W., S.A. Gerber, A.L. Sedlacek, V.Y. Rybalko, W.M. Chan, and E.M. Lord, Omental immune aggregates and tumor metastasis within the peritoneal cavity. Immunol Res, 2009. 45(2-3): p. 185-94.

66. Lopes Cardozo, A.M., A. Gupta, M.J. Koppe, S. Meijer, P.A. van Leeuwen, R.J. Beelen, et al., Metastatic pattern of CC531 colon carcinoma cells in the abdominal cavity: an experimental model of peritoneal carcinomatosis in rats. Eur J Surg Oncol, 2001. 27(4): p. 359-63.

67. Robinson-Smith, T.M., I. Isaacsohn, C.A. Mercer, M. Zhou, N. Van Rooijen, N. Husseinzadeh, et al., Macrophages mediate inflammation-enhanced metastasis of ovarian tumors in mice. Cancer Res, 2007. 67(12): p. 5708-16.

68. Takemori, N., K. Hirai, R. Onodera, N. Saito, and M. Namiki, Light and electron microscope study of splenoportal milky spots in New Zealand black mice: comparison between splenoportal milky spots and aberrant spleens. J Anat, 1995. 186 ( Pt 2): p. 287-99.

69. Schumann, T., T. Adhikary, A. Wortmann, F. Finkernagel, S. Lieber, E. Schnitzer, et al., Deregulation of PPARbeta/delta target genes in tumor-associated macrophages by fatty acid ligands in the ovarian cancer microenvironment. Oncotarget, 2015. 6(15): p. 13416-33.

70. Folkman, J., Tumor angiogenesis: therapeutic implications. N Engl J Med, 1971. 285(21): p. 1182-6.

71. Zhang, Q.X., C.J. Magovern, C.A. Mack, K.T. Budenbender, W. Ko, and T.K. Rosengart, Vascular endothelial growth factor is the major angiogenic factor in omentum: mechanism of the omentum-mediated angiogenesis. J Surg Res, 1997. 67(2): p. 147-54.

72. Choi, H.J., G.N. Armaiz Pena, S. Pradeep, M.S. Cho, R.L. Coleman, and A.K. Sood, Anti-vascular therapies in ovarian cancer: moving beyond anti-VEGF approaches. Cancer Metastasis Rev, 2015. 34(1): p. 19-40.

73. Krock, B.L., N. Skuli, and M.C. Simon, Hypoxia-induced angiogenesis: good and evil. Genes Cancer, 2011. 2(12): p. 1117-33.

74. Georgiou, K.R., S.K. Hui, and C.J. Xian, Regulatory pathways associated with bone loss and bone marrow adiposity caused by aging, chemotherapy, glucocorticoid therapy and radiotherapy. Am J Stem Cells, 2012. 1(3): p. 205-24.

75. Cawthorn, W.P., E.L. Scheller, B.S. Learman, S.D. Parlee, B.R. Simon, H. Mori, et al., Bone marrow adipose tissue is an endocrine organ that contributes to increased circulating adiponectin during caloric restriction. Cell Metab, 2014. 20(2): p. 368-75.

76. Bassett, W.W., M.R. Cooperberg, N. Sadetsky, S. Silva, J. DuChane, D.J. Pasta, et al., Impact of obesity on prostate cancer recurrence after radical prostatectomy: data from CaPSURE. Urology, 2005. 66(5): p. 1060-5.

77. Keto, C.J., W.J. Aronson, M.K. Terris, J.C. Presti, C.J. Kane, C.L. Amling, et al., Obesity is associated with castration-resistant disease and metastasis in men treated with androgen deprivation therapy after radical prostatectomy: results from the SEARCH database. BJU Int, 2012. 110(4): p. 492-498.

78. Gong, Z., I. Agalliu, D.W. Lin, J.L. Stanford, and A.R. Kristal, Obesity is associated with increased risks of prostate cancer metastasis and death after initial cancer diagnosis in middle-aged men. Cancer, 2007. 109(6): p. 1192202.

79. von Drygalski, A., T.B. Tran, K. Messer, M. Pu, S. Corringham, C. Nelson, et al., Obesity is an independent predictor of poor survival in metastatic breast cancer: retrospective analysis of a patient cohort whose treatment included high-dose chemotherapy and autologous stem cell support. Int J Breast Cancer, 2011. 2011: p. 523276. 
80. Ryden, M., M. Uzunel, J.L. Hard, E. Borgstrom, J.E. Mold, E. Arner, et al., Transplanted Bone Marrow-Derived Cells Contribute to Human Adipogenesis. Cell Metab, 2015. 22(3): p. 408-17.

81. Tavassoli, M., Ultrastructural development of bone marrow adipose cell. Acta Anat (Basel), 1976. 94(1): p. 65-77.

82. Chen, J., Y. Shi, J. Regan, K. Karuppaiah, D.M. Ornitz, and F. Long, Osx-Cre targets multiple cell types besides osteoblast lineage in postnatal mice. PLoS One, 2014. 9(1): p. e85161.

83. Liu, Y., S. Strecker, L. Wang, M.S. Kronenberg, W. Wang, D.W. Rowe, et al., Osterix-cre labeled progenitor cells contribute to the formation and maintenance of the bone marrow stroma. PLoS One, 2013. 8(8): p. e71318.

84. Bianco, P., X. Cao, P.S. Frenette, J.J. Mao, P.G. Robey, P.J. Simmons, et al., The meaning, the sense and the significance: translating the science of mesenchymal stem cells into medicine. Nat Med, 2013. 19(1): p. 35-42.

85. Mizoguchi, T., S. Pinho, J. Ahmed, Y. Kunisaki, M. Hanoun, A. Mendelson, et al., Osterix marks distinct waves of primitive and definitive stromal progenitors during bone marrow development. Dev Cell, 2014. 29(3): p. 340-9.

86. Zhou, B.O., R. Yue, M.M. Murphy, J.G. Peyer, and S.J. Morrison, Leptin-receptor-expressing mesenchymal stromal cells represent the main source of bone formed by adult bone marrow. Cell Stem Cell, 2014. 15(2): p. 154-68.

87. Worthley, D.L., M. Churchill, J.T. Compton, Y. Tailor, M. Rao, Y. Si, et al., Gremlin 1 identifies a skeletal stem cell with bone, cartilage, and reticular stromal potential. Cell, 2015. 160(1-2): p. 269-84.

88. Berendsen, A.D. and B.R. Olsen, Osteoblast-adipocyte lineage plasticity in tissue development, maintenance and pathology. Cell Mol Life Sci, 2014. 71(3): p. 493-7.

89. Wiren, K.M., A. Chapman Evans, and X.W. Zhang, Osteoblast differentiation influences androgen and estrogen receptor-alpha and -beta expression. J Endocrinol, 2002. 175(3): p. 683-94.

90. Reim, N.S., B. Breig, K. Stahr, J. Eberle, A. Hoeflich, E. Wolf, et al., Cortical bone loss in androgen-deficient aged male rats is mainly caused by increased endocortical bone remodeling. J Bone Miner Res, 2008. 23(5): p. 694704.

91. Ottewell, P.D., N. Wang, J. Meek, C.A. Fowles, P.I. Croucher, C.L. Eaton, et al., Castration-induced bone loss triggers growth of disseminated prostate cancer cells in bone. Endocr Relat Cancer, 2014. 21(5): p. 769-81.

92. Muruganandan, S., A.A. Roman, and C.J. Sinal, Adipocyte differentiation of bone marrow-derived mesenchymal stem cells: cross talk with the osteoblastogenic program. Cell Mol Life Sci, 2009. 66(2): p. 236-53.

93. Ali, A.A., R.S. Weinstein, S.A. Stewart, A.M. Parfitt, S.C. Manolagas, and R.L. Jilka, Rosiglitazone causes bone loss in mice by suppressing osteoblast differentiation and bone formation. Endocrinology, 2005. 146(3): p. 1226-35.

94. Grey, A., Skeletal consequences of thiazolidinedione therapy. Osteoporos Int, 2008. 19(2): p. 129-37.

95. Ackert-Bicknell, C.L., K.R. Shockley, L.G. Horton, B. Lecka-Czernik, G.A. Churchill, and C.J. Rosen, Strain-specific effects of rosiglitazone on bone mass, body composition, and serum insulin-like growth factor-I. Endocrinology, 2009. 150(3): p. 1330-40.

96. Lecka-Czernik, B., E.J. Moerman, D.F. Grant, J.M. Lehmann, S.C. Manolagas, and R.L. Jilka, Divergent effects of selective peroxisome proliferator-activated receptor-gamma 2 ligands on adipocyte versus osteoblast differentiation. Endocrinology, 2002. 143(6): p. 2376-84.

97. Bennett, C.N., H. Ouyang, Y.L. Ma, Q. Zeng, I. Gerin, K.M. Sousa, et al., Wnt10b increases postnatal bone formation by enhancing osteoblast differentiation. J Bone Miner Res, 2007. 22(12): p. 1924-32.

98. Cawthorn, W.P., A.J. Bree, Y. Yao, B. Du, N. Hemati, G. Martinez-Santibanez, et al., Wnt6, Wnt10a and Wnt10b inhibit adipogenesis and stimulate osteoblastogenesis through a beta-catenin-dependent mechanism. Bone, 2012. 50(2): p. 477-89.

99. Kang, S., C.N. Bennett, I. Gerin, L.A. Rapp, K.D. Hankenson, and O.A. Macdougald, Wnt signaling stimulates osteoblastogenesis of mesenchymal precursors by suppressing CCAAT/enhancer-binding protein alpha and peroxisome proliferator-activated receptor gamma. J Biol Chem, 2007. 282(19): p. 14515-24. 
100. Krishnan, V., H.U. Bryant, and O.A. Macdougald, Regulation of bone mass by Wnt signaling. J Clin Invest, 2006. 116(5): p. 1202-9.

101. Scheller, E.L., C.R. Doucette, B.S. Learman, W.P. Cawthorn, S. Khandaker, B. Schell, et al., Region-specific variation in the properties of skeletal adipocytes reveals regulated and constitutive marrow adipose tissues. Nat Commun, 2015. 6: p. 7808.

102. Doucette, C.R., M.C. Horowitz, R. Berry, O.A. MacDougald, R. Anunciado-Koza, R.A. Koza, et al., A High Fat Diet Increases Bone Marrow Adipose Tissue (MAT) But Does Not Alter Trabecular or Cortical Bone Mass in C57BL/6J Mice. J Cell Physiol, 2015. 230(9): p. 2032-7.

103. Botolin, S. and L.R. McCabe, Inhibition of PPARgamma prevents type I diabetic bone marrow adiposity but not bone loss. J Cell Physiol, 2006. 209(3): p. 967-76.

104. Iwaniec, U.T. and R.T. Turner, Failure to generate bone marrow adipocytes does not protect mice from ovariectomy-induced osteopenia. Bone, 2013. 53(1): p. 145-53.

105. Tavassoli, M., Marrow adipose cells. Histochemical identification of labile and stable components. Arch Pathol Lab Med, 1976. 100(1): p. 16-8.

106. van der Pluijm, G., Epithelial plasticity, cancer stem cells and bone metastasis formation. Bone, 2011. 48(1): p. 37-43.

107. Paget, S., The distribution of secondary growths in cancer of the breast. 1889. Cancer Metastasis Rev, 1989. 8(2): p. 98-101.

108. Lyden, D., K. Hattori, S. Dias, C. Costa, P. Blaikie, L. Butros, et al., Impaired recruitment of bone-marrow-derived endothelial and hematopoietic precursor cells blocks tumor angiogenesis and growth. Nat Med, 2001. 7(11): p. 1194-201.

109. Kaplan, R.N., R.D. Riba, S. Zacharoulis, A.H. Bramley, L. Vincent, C. Costa, et al., VEGFR1-positive haematopoietic bone marrow progenitors initiate the pre-metastatic niche. Nature, 2005. 438(7069): p. 820-7.

110. van der Horst, G., C. van den Hoogen, J.T. Buijs, H. Cheung, H. Bloys, R.C. Pelger, et al., Targeting of alpha(v)integrins in stem/progenitor cells and supportive microenvironment impairs bone metastasis in human prostate cancer. Neoplasia, 2011. 13(6): p. 516-25.

111. Herroon, M.K., E. Rajagurubandara, A.L. Hardaway, K. Powell, A. Turchick, D. Feldmann, et al., Bone marrow adipocytes promote tumor growth in bone via FABP4-dependent mechanisms. Oncotarget, 2013. 4(11): p. 210823.

112. Unruh, A., A. Ressel, H.G. Mohamed, R.S. Johnson, R. Nadrowitz, E. Richter, et al., The hypoxia-inducible factor-1 alpha is a negative factor for tumor therapy. Oncogene, 2003. 22(21): p. 3213-20.

113. Muller, A., B. Homey, H. Soto, N. Ge, D. Catron, M.E. Buchanan, et al., Involvement of chemokine receptors in breast cancer metastasis. Nature, 2001. 410(6824): p. 50-6.

114. Jung, Y., J.K. Kim, Y. Shiozawa, J. Wang, A. Mishra, J. Joseph, et al., Recruitment of mesenchymal stem cells into prostate tumours promotes metastasis. Nat Commun, 2013. 4: p. 1795.

115. Taichman, R.S., C. Cooper, E.T. Keller, K.J. Pienta, N.S. Taichman, and L.K. McCauley, Use of the stromal cellderived factor-1/CXCR4 pathway in prostate cancer metastasis to bone. Cancer Res, 2002. 62(6): p. 1832-7.

116. Kim, D., J. Kim, J.H. Yoon, J. Ghim, K. Yea, P. Song, et al., CXCL12 secreted from adipose tissue recruits macrophages and induces insulin resistance in mice. Diabetologia, 2014. 57(7): p. 1456-65.

117. Pantel, K., V. Muller, M. Auer, N. Nusser, N. Harbeck, and S. Braun, Detection and clinical implications of early systemic tumor cell dissemination in breast cancer. Clin Cancer Res, 2003. 9(17): p. 6326-34.

118. Aft, R., M. Naughton, K. Trinkaus, M. Watson, L. Ylagan, M. Chavez-MacGregor, et al., Effect of zoledronic acid on disseminated tumour cells in women with locally advanced breast cancer: an open label, randomised, phase 2 trial. Lancet Oncol, 2010. 11(5): p. 421-8.

This article is protected by copyright. All rights reserved. 
119. Ottewell, P.D., N. Wang, H.K. Brown, K.J. Reeves, C.A. Fowles, P.I. Croucher, et al., Zoledronic acid has differential antitumor activity in the pre- and postmenopausal bone microenvironment in vivo. Clin Cancer Res, 2014. 20(11): p. 2922-32.

120. Dunn, L.K., K.S. Mohammad, P.G. Fournier, C.R. McKenna, H.W. Davis, M. Niewolna, et al., Hypoxia and TGF-beta drive breast cancer bone metastases through parallel signaling pathways in tumor cells and the bone microenvironment. PLoS One, 2009. 4(9): p. e6896.

121. Yin, J.J., C.B. Pollock, and K. Kelly, Mechanisms of cancer metastasis to the bone. Cell Res, 2005. 15(1): p. 57-62.

122. Ghajar, C.M., H. Peinado, H. Mori, I.R. Matei, K.J. Evason, H. Brazier, et al., The perivascular niche regulates breast tumour dormancy. Nat Cell Biol, 2013. 15(7): p. 807-17.

123. Varma, V., A. Yao-Borengasser, A.M. Bodles, N. Rasouli, B. Phanavanh, G.T. Nolen, et al., Thrombospondin-1 is an adipokine associated with obesity, adipose inflammation, and insulin resistance. Diabetes, 2008. 57(2): p. 432-9.

124. Ramis, J.M., N.L. Franssen-van Hal, E. Kramer, I. Llado, F. Bouillaud, A. Palou, et al., Carboxypeptidase E and thrombospondin-1 are differently expressed in subcutaneous and visceral fat of obese subjects. Cell Mol Life Sci, 2002. 59(11): p. 1960-71.

125. Catena, R., N. Bhattacharya, T. El Rayes, S. Wang, H. Choi, D. Gao, et al., Bone marrow-derived Gr1+ cells can generate a metastasis-resistant microenvironment via induced secretion of thrombospondin-1. Cancer Discov, 2013. 3(5): p. 578-89.

126. Li, Y., X. Tong, C. Rumala, K. Clemons, and S. Wang, Thrombospondin1 deficiency reduces obesity-associated inflammation and improves insulin sensitivity in a diet-induced obese mouse model. PLoS One, 2011. 6(10): p. e26656.

127. Febbraio, M., D.P. Hajjar, and R.L. Silverstein, CD36: a class B scavenger receptor involved in angiogenesis, atherosclerosis, inflammation, and lipid metabolism. J Clin Invest, 2001. 108(6): p. 785-91.

128. Li, Y., X. Qi, X. Tong, and S. Wang, Thrombospondin 1 activates the macrophage Toll-like receptor 4 pathway. Cell Mol Immunol, 2013. 10(6): p. 506-12.

129. Elbaz, A., X. Wu, D. Rivas, J.M. Gimble, and G. Duque, Inhibition of fatty acid biosynthesis prevents adipocyte lipotoxicity on human osteoblasts in vitro. J Cell Mol Med, 2010. 14(4): p. 982-91.

130. Gunaratnam, K., C. Vidal, J.M. Gimble, and G. Duque, Mechanisms of palmitate-induced lipotoxicity in human osteoblasts. Endocrinology, 2014. 155(1): p. 108-16.

131. Li, G.W., Z. Xu, S.X. Chang, L. Zhou, X.Y. Wang, H. Nian, et al., Influence of early zoledronic acid administration on bone marrow fat in ovariectomized rats. Endocrinology, 2014. 155(12): p. 4731-8.

132. Martin, R.B. and S.L. Zissimos, Relationships between marrow fat and bone turnover in ovariectomized and intact rats. Bone, 1991. 12(2): p. 123-31.

133. Guise, T.A., K.S. Mohammad, G. Clines, E.G. Stebbins, D.H. Wong, L.S. Higgins, et al., Basic mechanisms responsible for osteolytic and osteoblastic bone metastases. Clin Cancer Res, 2006. 12(20 Pt 2): p. 6213s-6216s.

134. Schneider, A., L.M. Kalikin, A.C. Mattos, E.T. Keller, M.J. Allen, K.J. Pienta, et al., Bone turnover mediates preferential localization of prostate cancer in the skeleton. Endocrinology, 2005. 146(4): p. 1727-36.

135. Hardaway, A.L., M.K. Herroon, E. Rajagurubandara, and I. Podgorski, Marrow adipocyte-derived CXCL1 and CXCL2 contribute to osteolysis in metastatic prostate cancer. Clin Exp Metastasis, 2015. 32(4): p. 353-68.

136. De Filippo, K., A. Dudeck, M. Hasenberg, E. Nye, N. van Rooijen, K. Hartmann, et al., Mast cell and macrophage chemokines CXCL1/CXCL2 control the early stage of neutrophil recruitment during tissue inflammation. Blood, 2013. 121(24): p. 4930-7.

137. Acharyya, S., T. Oskarsson, S. Vanharanta, S. Malladi, J. Kim, P.G. Morris, et al., A CXCL1 paracrine network links cancer chemoresistance and metastasis. Cell, 2012. 150(1): p. 165-78. 
138. Shojaei, F., X. Wu, A.K. Malik, C. Zhong, M.E. Baldwin, S. Schanz, et al., Tumor refractoriness to anti-VEGF treatment is mediated by CD11b+Gr1+ myeloid cells. Nat Biotechnol, 2007. 25(8): p. 911-20.

139. Yang, L., L.M. DeBusk, K. Fukuda, B. Fingleton, B. Green-Jarvis, Y. Shyr, et al., Expansion of myeloid immune suppressor Gr+CD11b+ cells in tumor-bearing host directly promotes tumor angiogenesis. Cancer Cell, 2004. 6(4): p. 409-21.

140. Gabrilovich, D.I. and S. Nagaraj, Myeloid-derived suppressor cells as regulators of the immune system. Nat Rev Immunol, 2009. 9(3): p. 162-74.

141. El-Amm, J., A. Freeman, N. Patel, and J.B. Aragon-Ching, Bone-targeted therapies in metastatic castrationresistant prostate cancer: evolving paradigms. Prostate Cancer, 2013. 2013: p. 210686.

142. Basso, F.G., A.P. Silveira Turrioni, J. Hebling, and C.A. de Souza Costa, Zoledronic acid inhibits human osteoblast activities. Gerontology, 2013. 59(6): p. 534-41.

143. Li, G.W., S.X. Chang, J.Z. Fan, Y.N. Tian, Z. Xu, and Y.M. He, Marrow adiposity recovery after early zoledronic acid treatment of glucocorticoid-induced bone loss in rabbits assessed by magnetic resonance spectroscopy. Bone, 2013. 52(2): p. 668-75.

144. Pozzi, S., S. Vallet, S. Mukherjee, D. Cirstea, N. Vaghela, L. Santo, et al., High-dose zoledronic acid impacts bone remodeling with effects on osteoblastic lineage and bone mechanical properties. Clin Cancer Res, 2009. 15(18): p. 5829-39.

145. Morgans, A.K. and M.R. Smith, Bone-targeted agents: preventing skeletal complications in prostate cancer. Urol Clin North Am, 2012. 39(4): p. 533-46.

146. Saad, F., D.M. Gleason, R. Murray, S. Tchekmedyian, P. Venner, L. Lacombe, et al., A randomized, placebocontrolled trial of zoledronic acid in patients with hormone-refractory metastatic prostate carcinoma. J Natl Cancer Inst, 2002. 94(19): p. 1458-68.

147. Smith, M.R., S. Halabi, C.J. Ryan, A. Hussain, N. Vogelzang, W. Stadler, et al., Randomized controlled trial of early zoledronic acid in men with castration-sensitive prostate cancer and bone metastases: results of CALGB 90202 (alliance). J Clin Oncol, 2014. 32(11): p. 1143-50.

148. Coleman, R., T. Powles, A. Paterson, M. Gnant, S. Anderson, I. Diel, et al., Adjuvant bisphosphonate treatment in early breast cancer: meta-analyses of individual patient data from randomised trials. Lancet, 2015. 386(10001): p. 1353-61.

149. Sumida, T., Clinical and experimental study on fatty acid composition of bone marrow lipid in hematologic disorders. Acta Med Nagasaki, 1965. 9(3): p. 222-41.

150. Denizot, Y., C. Dulery, F. Trimoreau, V. Desplat, and V. Praloran, Arachidonic acid and human bone marrow stromal cells. Biochim Biophys Acta, 1998. 1402(2): p. 209-15.

151. Denizot, Y., V. Desplat, C. Dulery, F. Trimoreau, and V. Praloran, Arachidonic acid and freshly isolated human bone marrow mononuclear cells. Mediators Inflamm, 1999. 8(1): p. 31-5.

152. Brown, M.D., C.A. Hart, E. Gazi, S. Bagley, and N.W. Clarke, Promotion of prostatic metastatic migration towards human bone marrow stoma by Omega 6 and its inhibition by Omega 3 PUFAs. Br J Cancer, 2006. 94(6): p. 84253.

153. Brown, M.D., C. Hart, E. Gazi, P. Gardner, N. Lockyer, and N. Clarke, Influence of omega-6 PUFA arachidonic acid and bone marrow adipocytes on metastatic spread from prostate cancer. Br J Cancer, 2010. 102(2): p. 403-13.

154. Gazi, E., P. Gardner, N.P. Lockyer, C.A. Hart, M.D. Brown, and N.W. Clarke, Direct evidence of lipid translocation between adipocytes and prostate cancer cells with imaging FTIR microspectroscopy. J Lipid Res, 2007. 48(8): p. 1846-56.

155. Rose, D.P., Effects of dietary fatty acids on breast and prostate cancers: evidence from in vitro experiments and animal studies. Am J Clin Nutr, 1997. 66(6 Suppl): p. 1513S-1522S. 
156. Hughes-Fulford, M., C.F. Li, J. Boonyaratanakornkit, and S. Sayyah, Arachidonic acid activates phosphatidylinositol 3-kinase signaling and induces gene expression in prostate cancer. Cancer Res, 2006. 66(3): p. 1427-33.

157. Tjandrawinata, R.R., R. Dahiya, and M. Hughes-Fulford, Induction of cyclo-oxygenase-2 mRNA by prostaglandin E2 in human prostatic carcinoma cells. Br J Cancer, 1997. 75(8): p. 1111-8.

158. Kurtova, A.V., J. Xiao, Q. Mo, S. Pazhanisamy, R. Krasnow, S.P. Lerner, et al., Blocking PGE2-induced tumour repopulation abrogates bladder cancer chemoresistance. Nature, 2015. 517(7533): p. 209-13.

159. Ghosh, J., Rapid induction of apoptosis in prostate cancer cells by selenium: reversal by metabolites of arachidonate 5-lipoxygenase. Biochem Biophys Res Commun, 2004. 315(3): p. 624-35.

160. Gao, X., D.J. Grignon, T. Chbihi, A. Zacharek, Y.Q. Chen, W. Sakr, et al., Elevated 12-lipoxygenase mRNA expression correlates with advanced stage and poor differentiation of human prostate cancer. Urology, 1995. 46(2): p. 227-37.

161. Nie, D., G.G. Hillman, T. Geddes, K. Tang, C. Pierson, D.J. Grignon, et al., Platelet-type 12-lipoxygenase in a human prostate carcinoma stimulates angiogenesis and tumor growth. Cancer Res, 1998. 58(18): p. 4047-51.

162. Norrish, A.E., C.M. Skeaff, G.L. Arribas, S.J. Sharpe, and R.T. Jackson, Prostate cancer risk and consumption of fish oils: a dietary biomarker-based case-control study. Br J Cancer, 1999. 81(7): p. 1238-42.

163. Rose, D.P. and J.M. Connolly, Omega-3 fatty acids as cancer chemopreventive agents. Pharmacol Ther, 1999. 83(3): p. 217-44.

164. Watkins, B.A., Y. Li, K.G. Allen, W.E. Hoffmann, and M.F. Seifert, Dietary ratio of $(n-6) /(n-3)$ polyunsaturated fatty acids alters the fatty acid composition of bone compartments and biomarkers of bone formation in rats. J Nutr, 2000. 130(9): p. 2274-84.

165. Mamalakis, G., A. Kafatos, N. Kalogeropoulos, N. Andrikopoulos, G. Daskalopulos, and A. Kranidis, Prostate cancer vs hyperplasia: relationships with prostatic and adipose tissue fatty acid composition. Prostaglandins Leukot Essent Fatty Acids, 2002. 66(5-6): p. 467-77.

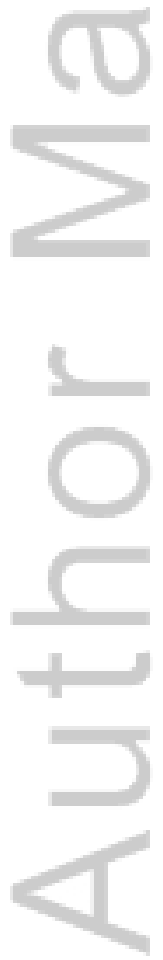


Table 1: Oncomine analysis of mRNA expression of genes involved in fatty acid binding, uptake, synthesis, and metabolism in ovarian cancer patients. "The Oncomine database (Oncomine ${ }^{\mathrm{TM}} \mathrm{v} 4.5$ : 729 datasets, 91,866 samples) was used for the analysis of primary (P) vs. metastatic (M) tumors. Following genes were analyzed: Fatty acid binding protein 4 (FABP4), Cluster of differentiation (CD36; FAT), Fatty acid synthase (FASN), Hormone sensitive lipase (HSL), Perilipin2 (PLIN2); $\mathrm{n}=$ number of samples. Data were ordered by 'overexpression' and the threshold was adjusted to Pvalue $<1 \mathrm{E}^{-} 4$; fold change, 2 and gene rank, top $10 \%$. For each database, only genes that met the criteria for significance are reported".

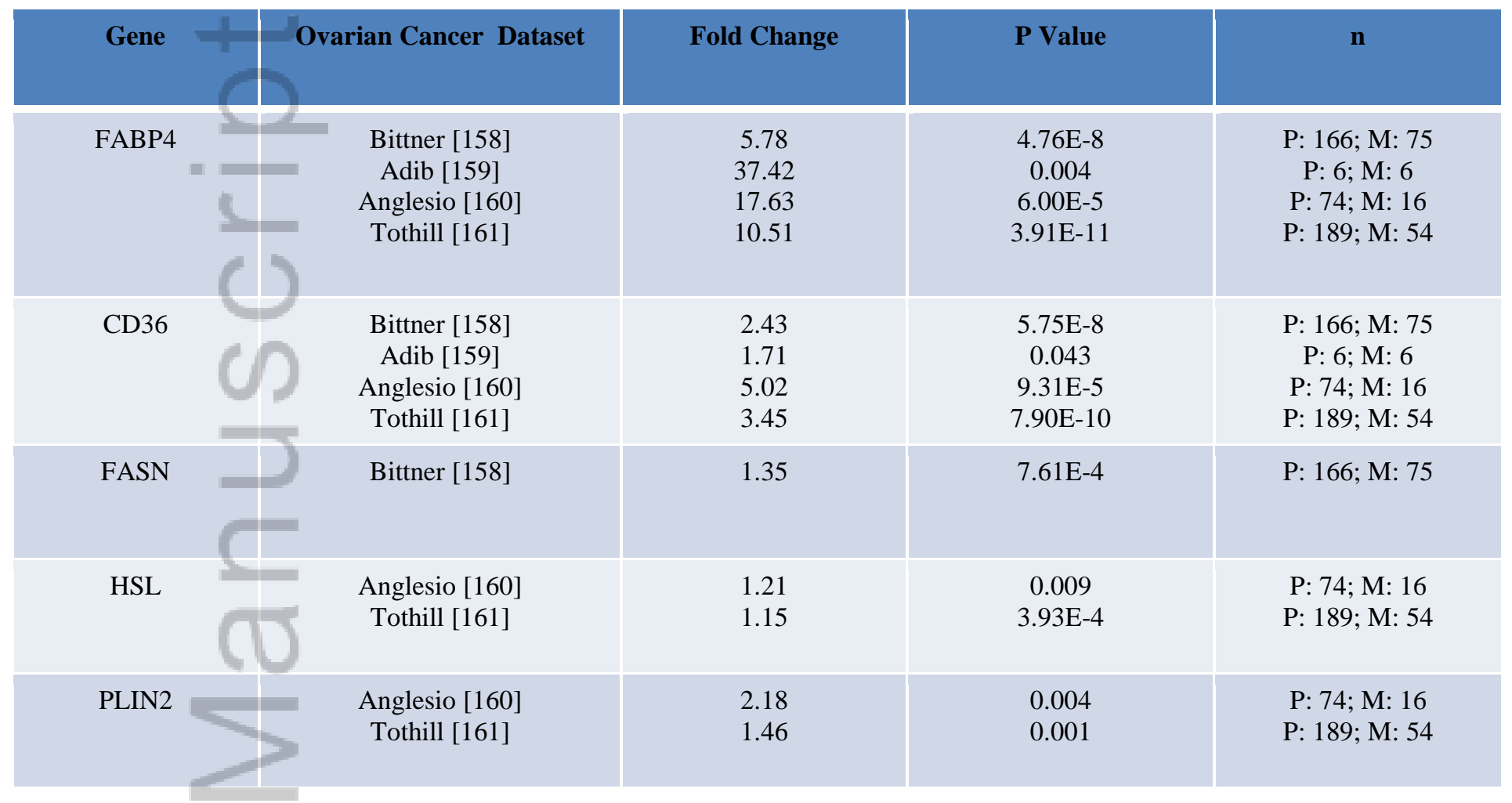


Table 2: Oncomine (Oncomine $\mathrm{C}^{\mathrm{TM}} \mathrm{v} 4.5$ ) analysis of mRNA expression of genes involved in fatty acid binding, uptake, synthesis, and metabolism in patients with metastatic ovarian cancer sites $(M)$ compared to primary sites $(P)$. Following genes were analyzed: Vascular endothelial growth factor receptor-1 (VEGFR1) and -2 (VEGFR2), Cluster of differentiation 31 (CD31), and cluster of differentiation 34 (CD34); n = number of samples. Data were ordered by 'overexpression' and the threshold was adjusted to P-value <1E-4; fold change, 2 and gene rank, top 10\%. For each database, only genes that met the criteria for significance are reported".

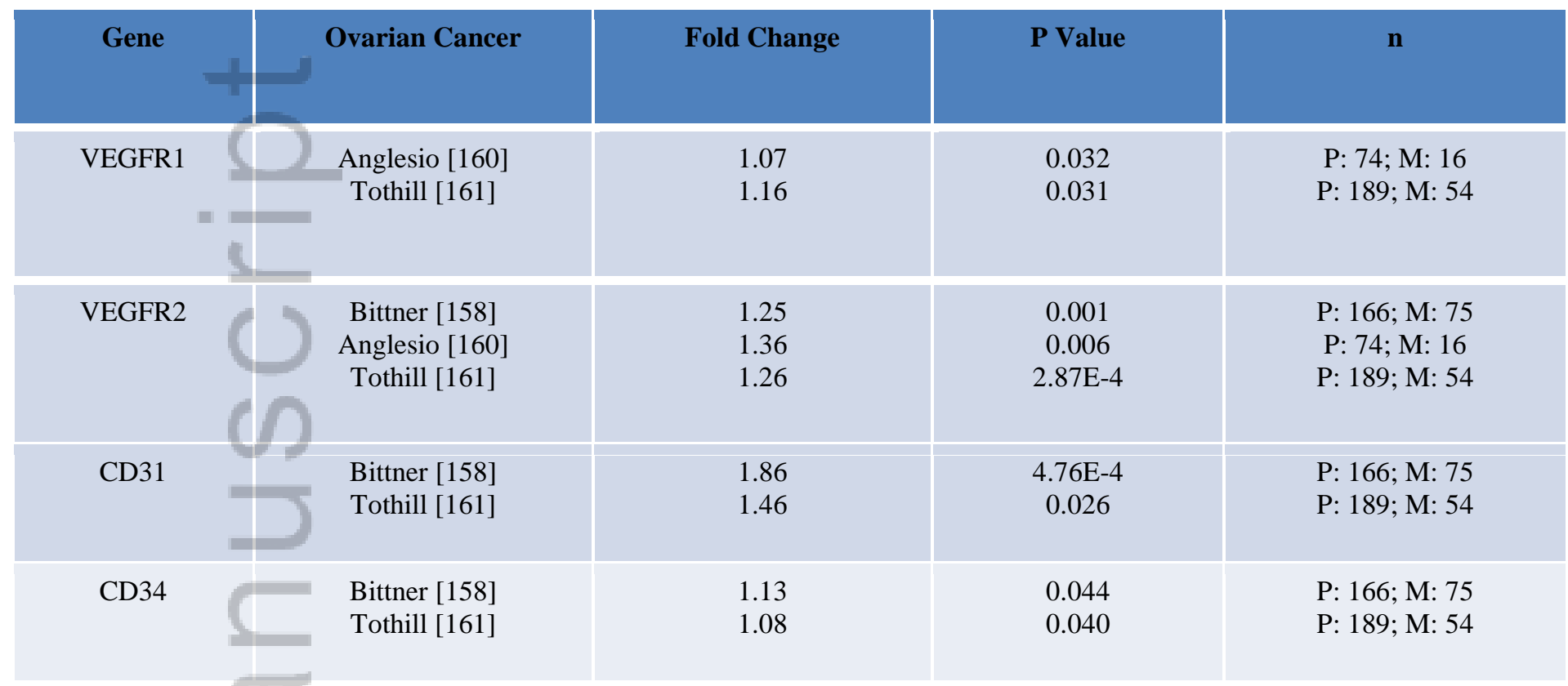


Table 3. Oncomine (Oncomine $\mathrm{T}^{\mathrm{T}} \mathrm{v} 4.5$ ) analysis of mRNA expression of genes involved in fatty acid binding, uptake, synthesis, and metabolism in patients with metastatic prostate cancer sites (M) compared to primary sites (P). Following genes were analyzed: Vascular endothelial growth factor receptor-1 (VEGFR1) and -2 (VEGFR2), Cluster of differentiation 31 (CD31), and cluster of differentiation $34(\mathrm{CD} 34) ; \mathrm{n}=$ number of samples. Data were ordered by 'overexpression' and the threshold was adjusted to P-value <1E 4; fold change, 2 and gene rank, top 10\%. For each database, only genes that met the criteria for significance are reported".

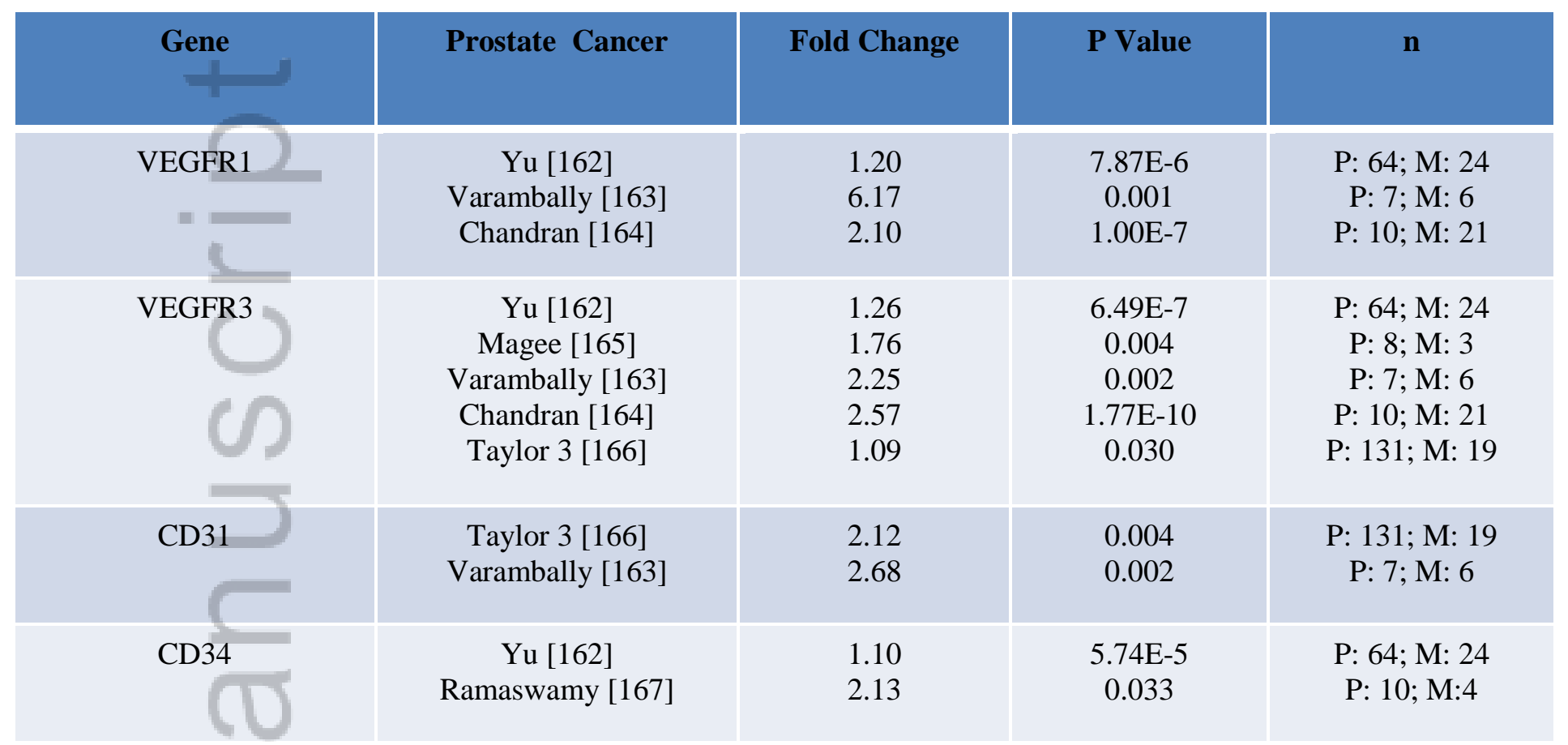


Table 4: Oncomine (Oncomine $\left.{ }^{\mathrm{TM}} \mathrm{v} 4.5\right)$ analysis of mRNA expression of genes involved in fatty acid binding, uptake, synthesis, and metabolism in patients with metastatic prostate cancer sites (M) compared to primary sites (P). Following genes were analyzed: Fatty acid binding protein 4 (FABP4), Cluster of differentiation (CD36; FAT), Fatty acid synthase (FASN), Hormone sensitive lipase (HSL), Perilipin2 (PLIN2); Fatty Acid Transporter Protein Family members (FATP 1-6); $\mathrm{n}=$ number of samples. Data were ordered by 'overexpression' and the threshold was adjusted to P-value <1E-4; fold change, 2 and gene rank, top 10\%. For each database, only genes that met the criteria for significance are reported".

\begin{tabular}{|c|c|c|c|c|}
\hline Gene & Prostate Cancer & Fold Change & P Value & $\mathbf{n}$ \\
\hline FABP4 & $\begin{array}{c}\text { Grasso [168] } \\
\text { Chandran [164] } \\
\text { Yu [162] } \\
\text { Holzbeierlein [169] } \\
\text { Ramaswamy [167] } \\
\text { Ramaswamy 2 [170] } \\
\text { Tamura [171] } \\
\text { LaTulippe [172] }\end{array}$ & $\begin{array}{c}2.16 \\
12.32 \\
2.14 \\
2.79 \\
6.37 \\
5.86 \\
2.23 \\
6.87\end{array}$ & $\begin{array}{c}0.024 \\
2.20 \mathrm{E}-6 \\
0.001 \\
0.015 \\
0.013 \\
0.018 \\
0.005 \\
0.003\end{array}$ & $\begin{array}{l}\text { P: } 59 ; \mathrm{M}: 35 \\
\text { P: } 10 ; \mathrm{M}: 21 \\
\text { P: } 64 ; \mathrm{M}: 24 \\
\text { P: } 40 ; \mathrm{M}: 9 \\
\text { P: } 10 ; \mathrm{M}: 4 \\
\text { P: } 10 ; \mathrm{M}: 3 \\
\text { P: } 25 ; \mathrm{M}: 12 \\
\text { P: } 23 ; \mathrm{M}: 9\end{array}$ \\
\hline $\mathrm{CD} 36$ & $\begin{array}{c}\text { Grasso [168] } \\
\text { Varambally [163] } \\
\text { Chandran [164] } \\
\text { Yu [162] }\end{array}$ & $\begin{array}{l}2.73 \\
2.95 \\
2.98 \\
1.15\end{array}$ & $\begin{array}{c}0.024 \\
5.34 \mathrm{E}-4 \\
0.001 \\
8.02 \mathrm{E}-6\end{array}$ & $\begin{array}{l}\text { P: } 59 ; \mathrm{M}: 35 \\
\text { P:7; M: } 6 \\
\text { P: } 10 ; \text { M: } 21 \\
\text { P: 64; M: } 24\end{array}$ \\
\hline FASN & $\begin{array}{c}\text { Grasso [168] } \\
\text { Chandran [164] } \\
\text { Yu [162] } \\
\text { Holzbeierlein [169] } \\
\text { Ramaswamy [167] } \\
\text { Ramaswamy 2 [170] } \\
\text { Tamura [171] }\end{array}$ & $\begin{array}{c}2.49 \\
1.66 \\
1.76 \\
1.67 \\
8.89 \\
12.96 \\
2.04\end{array}$ & $\begin{array}{c}6.67 \mathrm{E}-5 \\
0.041 \\
5.23 \mathrm{E}-4 \\
0.029 \\
0.002 \\
0.004 \\
0.018\end{array}$ & $\begin{array}{l}\text { P: } 59 ; \text { M: } 35 \\
\text { P: } 10 ; \text { M: } 21 \\
\text { P: 64; M: } 24 \\
\text { P: } 40 ; \text { M: } 9 \\
\text { P: } 10 ; \text { M: } 4 \\
\text { P: } 10 ; M: 3 \\
\text { P: } 25 ; \text { M: } 12\end{array}$ \\
\hline HSL & $\begin{array}{c}\text { Chandran [164] } \\
\text { Lapointe [173] } \\
\text { LaTulippe [172] } \\
\text { Ramaswamy [167] } \\
\text { Grasso [168] } \\
\text { Yu [162] }\end{array}$ & $\begin{array}{l}1.62 \\
1.20 \\
1.20 \\
5.96 \\
1.80 \\
1.10\end{array}$ & $\begin{array}{c}1.23 \mathrm{E}-7 \\
0.004 \\
0.042 \\
0.027 \\
2.93 \mathrm{E}-5 \\
7.50 \mathrm{E}-5\end{array}$ & $\begin{array}{l}\text { P: } 10 ; \text { M: } 21 \\
\text { P: } 62 ; \text { M: } 9 \\
\text { P: 23; M: } 9 \\
\text { P: } 10 ; \text { M: } 4 \\
\text { P: 59; M: } 35 \\
\text { P: 64; M: } 24\end{array}$ \\
\hline PLIN2 & $\begin{array}{c}\text { Chandran [164] } \\
\text { Vanaja [174] } \\
\text { Yu [162] }\end{array}$ & $\begin{array}{l}1.98 \\
2.08 \\
1.77\end{array}$ & $\begin{array}{c}8.28 \mathrm{E}-4 \\
0.007 \\
9.59 \mathrm{E}-5\end{array}$ & $\begin{array}{l}\text { P: } 10 ; M: 21 \\
\text { P: } 27 ; M: 5 \\
\text { P: } 64 ; M: 24\end{array}$ \\
\hline
\end{tabular}




\begin{tabular}{|c|c|c|c|c|}
\hline FATP1 & Grasso [168] & 2.04 & $2.33 \mathrm{E}-7$ & P: 59; M: 35 \\
\hline FATP2 & Varambally [163] & 1.46 & 0.012 & P:7; M: 6 \\
\hline FATP3 & $\begin{array}{c}\text { Lapointe [173] } \\
\text { Grasso [168] } \\
\text { Varambally [163] }\end{array}$ & $\begin{array}{c}1.66 \\
1.53 \\
2.11\end{array}$ & $\begin{array}{c}0.005 \\
3.96 \mathrm{E}-5 \\
0.014\end{array}$ & $\begin{array}{l}\text { P: } 62 ; \mathrm{M}: 9 \\
\text { P: 59; M: } 35 \\
\text { P:7; M: } 6\end{array}$ \\
\hline FATP4 & $\begin{array}{c}\text { Grasso [168] } \\
\text { Varambally [163] }\end{array}$ & $\begin{array}{l}1.20 \\
1.58\end{array}$ & $\begin{array}{l}0.037 \\
0.002\end{array}$ & $\begin{array}{l}\text { P: } 59 ; M: 35 \\
\text { P:7; M: } 6\end{array}$ \\
\hline FATP5 & Chandran [164] & 2.20 & $2.12 \mathrm{E}-8$ & P: $10 ; M: 21$ \\
\hline FATP6 & Chandran [164] & 1.40 & 0.029 & P: 10; M: 21 \\
\hline
\end{tabular}

This article is protected by copyright. All rights reserved. 